Published in: L. Bolzoni, P.G. Esteban, E.M. Ruiz-Navas and E. Gordo, Mechanical behaviour of pressed and sintered titanium alloys obtained from prealloyed and blended elemental powders, Journal of the Mechanical Behavior of Biomedical Materials, Oct. 2012, v. 14, p. 29-38, http://dx.doi.org/10.1016/j.jmbbm.2012.05.013

(c) Elsevier 2012 


\title{
Mechanical Behaviour of Pressed and Sintered Titanium Alloys Obtained from Prealloyed and Blended Elemental Powders
}

\author{
L. Bolzoni, P.G. Esteban, E.M. Ruiz-Navas, E. Gordo \\ Departamento de Ciencia e Ingeniería de Materiales e Ingeniería Química \\ Universidad Carlos III de Madrid \\ Avda. de la Universidad, 30, 28911 Leganés (Madrid), Spain \\ e-mail: Ibolzoni@ing.uc3m.es, bolzoni.leandro@gmail.com
}

\begin{abstract}
The applicability of irregular prealloyed Ti-6AI-4V powder for the fabrication of titanium products by pressing and sintering and its employment as a master alloy to obtain the Ti-3Al-2.5V alloy was studied. To this end, the starting powders were characterised by dilatometry, differential thermal analysis and XRD. Green samples were obtained by cold uniaxial pressing, and the evolution of the microstructure over a sintering temperature range of $900-1400 \circ \mathrm{C}$ was studied. The variation of the final density and mechanical properties with the sintering temperature was considered. Based on the study carried out, it can be stated that more reliable powders are needed to open the titanium market to new applications. A relative density of $95 \%$ and diverse microstructural features and mechanical properties equivalent to those of biomedical devices can be obtained by the pressing and sintering route.
\end{abstract}

Keywords: Ti-3Al-2.5V, Ti-6Al-4V, titanium PM, prealloyed (PA), blending elemental (BE), flexural strength 


\section{Introduction}

Titanium and its alloys have been widely used over the past 50 years. Through the combination of various properties, they provide low density, good mechanical properties, biocompatibility and corrosion resistance (Lütjering and Williams, 2003). The workhorse alpha/beta Ti-6Al-4V alloy was one of the first titanium alloys to have been developed, and it has been employed in many critical sectors such as the aeronautical and medical fields (Leyens and Peters, 2003). On the other hand, Ti-3Al-2.5V alloy, known as "half Ti64", is classified as a near-alpha alloy due to the beta stabilising effect of vanadium; moreover, it has been developed primarily for the production of seamless pipes used in aircraft applications, such as hydraulic and fuel systems (Boyer et al., 1998). Currently, this alloy is also used to fabricate sports equipment, such as tennis racquets, due to its torsion resistance and medical and dental implants due to its corrosion resistance. The employment of the powder metallurgy route to obtain titanium products should lead to a reduction in production costs due to the intrinsic advantages of this processing technique and avoid the segregation of heavy alloying elements (Niinomi, 2002). The two classical approaches followed in titanium powder metallurgy are prealloying (PA)-normally, spherical powders are processed by advanced $\mathrm{P} / \mathrm{M}$ methods such as hot isostatic pressing (HIP) or metal injection moulding (MIM)-and blending elemental (BE), through which elemental titanium sponge fines are mixed either with elemental powders or with master alloys (Parsons et al., 1984). Over the past few decades, the hydride-dehydride (HDH) process has been employed for the fabrication of titanium and titanium alloys powders due to the great affinity of titanium for hydrogen, an element that brittles titanium and allows for the production of titanium powders by comminution processes, eliminating the problems related to the presence of chlorides, which are derived from the Kroll's process.

In this study, the conventional powder metallurgy route of pressing and sintering was employed to study the evolution of the microstructure of a prealloyed $\mathrm{HDH}$ Ti-6Al-4V powder with sintering temperature. The prealloyed nature of the powder studied should prevent the formation of coarse Kirkendall pores and heterogeneities normally induced by the different diffusion rate of the elemental alloying element powders. Moreover, the same HDH Ti-6Al-4V powder was employed as a "master alloy" for the production of the Ti-3Al-2.5V titanium alloy using the BE approach, and its microstructural evolution was studied. In this case, the employment of a master alloy instead of an elemental powder should prevent the exothermic reaction between elemental titanium and elemental aluminium that normally takes place at approximately 660ㄷ (Böhm and Kieback, 1998). Moreover, until recently, the main approach 
followed in the production of orthopaedic materials involved the adaptation of existing materials (Dewidar et al., 2006); therefore, there have been no studies on the production of Ti-3Al-2.5V by pressing and sintering, even though hot-pressing has been considered (Bolzoni et al., 2012a; Bolzoni et al., 2012b).

\section{Experimental Procedure}

Prealloyed HDH Ti-6AI-4V powder, which was purchased from Se-Jong Materials Co. Ltd., presents a typical angular morphology, and it is therefore suitable for the pressing and sintering route. Elemental titanium powder was acquired from GfE Gesellschaft für Elektrometallurgie mbH. The characteristics of the starting powders, provided by the suppliers, are reported in Table 1.

The blending of the elemental titanium with the Ti-6Al-4V powder to fabricate the Ti-3Al-2.5V powder blend was carried out in a "turbula" mixer for 30 minutes. XRD patterns of the powders were obtained using a Bruker AXS D8-Advance analyser over the range 20-120․ The powders were cold uniaxially pressed by applying a pressure of $400 \mathrm{MPa}$ and $300 \mathrm{MPa}$ for the prealloyed Ti-6Al-4V powder and the Ti$3 \mathrm{Al}-2.5 \mathrm{~V}$ powder blend, respectively, to prevent the delamination of the samples. To prevent contamination, no lubricant was added or mixed in the powder, though zinc stearate was used as a diewall lubricant. A dilatometric study carried out using a NETZSCH DIL 402 E dilatometer and differential thermal analysis carried out using a Netzsch STA 449 C Júpiter DTA were performed under an inert atmosphere ( $\mathrm{Ar}$ ). The specimens were sintered under high vacuum (approximately $10^{-5} \mathrm{mbar}$ ) over temperatures ranging from $900{ }^{\circ} \mathrm{C}$ to $1400 \circ \mathrm{C}$; they were then furnace cooled at $5 \circ \mathrm{C} / \mathrm{min}$ after a dwell time of 2 hours. For metallographic preparation, the samples were cut, ground using silicon carbide paper and polished with silica gel. To reveal the microconstituents of the specimens, the samples were chemically etched by using Kroll's reagent. Microstructural analysis was performed using scanning electron microscopy in the BSE mode, and the distribution of the alloying elements was verified by EDS. XRD diffraction of the sintered specimens was performed using an instrument equipped with a monochromator, which allowed for the exclusive use of the $\mathrm{K} \alpha_{1}$ radiation line of copper. Finally, the sintered samples were characterised in terms of flexural strength determined by means of three-point bending tests (ASTM B528) as well as Vickers hardness. 


\section{Results and Discussion}

\subsection{XRD analysis of the powders}

XRD analysis of the starting powders was carried out to identify the phases that compose the alloys. The XRD pattern representative of both the prealloyed Ti-6Al-4V powder and the Ti-3Al-2.5V powder blend is shown in Figure 1.

The main phase found during the XRD analysis of the powders (Figure 1) is the alpha phase, although some beta phase and some aluminium/vanadium phase, identified as $\mathrm{Al}_{2} \mathrm{~V}_{3}$, were detected, indicating that the composition of the prealloyed Ti-6Al-4V powder is not completely homogeneous. Nevertheless, the presence of the beta peak in the powder indicates that the alloying elements were actually already dissolved in the titanium matrix, thus stabilising the beta phase.

\subsection{Differential Thermal Analysis (DTA)}

DTA measurements were performed on loose powders by continuously heating up to $1400^{\circ} \mathrm{C}$ using a heating rate of $10^{\circ} \mathrm{C} / \mathrm{min}$, followed by a dwell step of 15 minutes at the maximum temperature and cooling down to room temperature $(10 \circ \mathrm{C} / \mathrm{min})$. The results of the DTA analysis are presented in Figure 2.

An analysis of the DTA heating curves shown in Figure 2 reveals two types of reactions. The very wide exothermic peak from approximately $420 \circ \mathrm{C}$ to $580 \circ \mathrm{C}$ for the Ti-6Al-4V powder is most likely due to some interaction between the loose powder and the crucible or the oxidation of the powder, even though an inert atmosphere was employed ( $\mathrm{Ar}$ ), and the endothermic peak at approximately $900{ }^{\circ} \mathrm{C}$ corresponds to the $\alpha$ to $\beta$ phase transformation. Furthermore, the endothermic peak detected for the prealloyed Ti-6Al-4V powder is almost negligible because the prealloyed powder was already composed of both the alpha and beta phases. Nevertheless, the onset temperature and the top of the peak are lower than the nominal beta transus of this alloy as shown in Table 2, which is most likely due to the inhomogeneity of the starting powder.

On the other hand, the endothermic phase transformation peak of the Ti-3Al-2.5V powder blend, which is shown in the inset of Figure 2, is much more marked, but once again the onset temperature and the 
top of the peak are lower than the nominal beta transus (see Table 2). This is because the Ti-3Al-2.5V powder blend was obtained by mixing the prealloyed powder with elemental titanium. It is worth mentioning that DTA analysis corroborates the notion that the use of a master alloy instead of elemental powder prevents the exothermic reaction between titanium and aluminium at $660^{\circ} \mathrm{C}$, which leads to the formation of the intermetallic $\mathrm{TiAl}_{3}$, which would somehow hinder the consolidation of the material (Böhm and Kieback, 1998).

\section{$\underline{3.3 \text { Dilatometric study }}$}

In conjunction with the DTA analysis, a dilatometric study was performed using the same thermal cycle (maximum temperature of $1400^{\circ} \mathrm{C}$, dwell time of 15 minutes and heating rate of $10 \circ \mathrm{C} / \mathrm{min}$ ) but on cold uniaxially pressed green samples with a parallelepiped geometry $\left(5 \times 5 \times 12 \mathrm{~mm}^{3}\right)$ instead of loose powders. Throughout the entire thermal cycle, a constant flow of $90 \mathrm{mlargon} / \mathrm{min}$ was used to prevent the oxidation of the specimens. The results obtained from the dilatometric study, represented as length variation versus temperature, are shown in Figure 3, and some details, namely maximum length variation and onset temperature, are reported in Table 3.

Figure 3 shows that the powders starts to sinter at approximately $750 \circ \mathrm{C}$ and the shrinkage of the Ti-6Al$4 \mathrm{~V}$ alloy begins slightly earlier than that of the Ti-3Al-2.5V powder blend. Actually, the data in Table 3 show that there is a delay of $90^{\circ} \mathrm{C}$ in terms of the onset temperature between the two materials. This delay is most likely because for the Ti-3Al-2.5V powder blend some of the thermal energy supplied is invested in the homogenisation of the composition. In any case, the shrinkage rates of the two alloys during heating over the temperature range 950-1400ㅇ $\mathrm{C}$ are similar: $1.96 \times 10^{-4} \mathrm{o}^{-1}$ and $2.11 \times 10^{-4} \mathrm{o}^{-1}$ for Ti-6AI-4V and Ti-3Al-2.5V, respectively. Moreover, the Ti-3Al-2.5V powder blend shows a slightly higher total shrinkage of approximately $0.5 \%$. It is worth mentioning that no swelling of the sample was detected near $660^{\circ} \mathrm{C}$ during the dilatometric analysis, which is usually observed when the Ti-6Al-4V alloy is fabricated using elemental powder (Ivasishin, 2005). 
The microstructural evolution of the prealloyed Ti-6Al-4V powder during vacuum sintering over the range $900-1400 \circ \mathrm{C}$ is shown in Figure 4.

The microstructural analysis of the Ti-6Al-4V prealloyed samples sintered at $9000^{\circ} \mathrm{C}$ (Figure 4 a) shows that the sintering of the powder particles was already initiated, in agreement with the results of the dilatometric study (Figure 3), because the interparticle boundaries were observed to disappear and the residual porosity was mostly irregular in shape. The microstructural analysis also indicates that the main microconstituent is the alpha phase, though isolated two-phase $\alpha+\beta$ islands are homogeneously distributed throughout the microstructure. Moreover, the microstructure is not completely homogeneous, and there are some alloying elements that diffuse, as indicated by results of the DTA and XRD.

Figure 5 shows a BSE-SEM image of one of the zones where diffusion takes place in the specimens sintered at $900{ }^{\circ} \mathrm{C}$ and the relative variation in the percentage of the alloying elements.

An EDS analysis of the darker zone observed during the microstructural analysis indicates that the percentage of titanium decreases from the centre of the powder particle, whereas the content of aluminium increases, indicating a faster diffusion of aluminium towards the titanium matrix. Moreover, Figure 5 shows that this inhomogeneous zone is surrounded by pores, which may be due to the limited diffusion induced by the sintering temperature employed, though it is also affected by the Kirkendall effect and therefore by differences in the diffusion rates.

A sintering temperature of $1000{ }^{\circ} \mathrm{C}$ (Figure $4 \mathrm{~b}$ ) leads to a pore structure constituted mainly of isolated pores, though the presence of highly irregular pores measuring approximately $30 / 40 \mu \mathrm{m}$, which are derived from the joining of diverse neighbouring pores, can also be observed. In general, the composition of the Ti-6Al-4V prealloyed samples sintered at $1000{ }^{\circ} \mathrm{C}$ is much more homogeneous, but there are still some darker zones dispersed throughout the matrix, which are characterised by a slightly higher aluminium content, as indicated by the EDS analysis.

Starting from a sintering temperature of $1100^{\circ} \mathrm{C}$ (Figure $4 \mathrm{c}-\mathrm{f}$ ), the percentage of residual porosity is reduced, the shape of the pores becomes more spherical and the pore structure is constituted by isolated pores. Moreover, the diffusion of the alloying elements seems to be complete, and the distribution of the elements is homogeneous. The EDS analysis indicates that the distribution of the alloying elements is homogenous because the average composition in weight percentage is 90.1Ti-6.1Al$3.8 \mathrm{~V}$. 
The results of the chemical analysis performed on the alpha grains and on the beta lamellae are shown in Table 4.

The results of the EDS analysis of the two phases that constitute the microstructure of the Ti-6AI-4V alloy (Table 4) resemble those of the compositional analysis, where the variation in the percentage of the alloying elements is due to the limited area of the zones analysed. What is interesting is that the percentage of vanadium dissolved in the alpha phase, approximately 1.3 at.\%, agrees with the binary Ti$V$ phase diagram, where the maximum solubility of vanadium in alpha titanium is 3 at.\% and may be somewhat lower due to the presence of impurities (Murray, 1987). Therefore, considering the data shown in Table 4, the general atomic percentage compositions of the alpha and beta phase are 87.9Ti10.7Al-1.3V and 82.8Ti-7.7Al-9.5V, respectively.

\subsection{Microstructural evolution during sintering of the Ti-3Al-2.5V alloy}

Figure 6 shows the microstructural evolution of the elementally blended Ti-3Al-2.5V powder blend during vacuum sintering between $900^{\circ} \mathrm{C}$ and $1400^{\circ} \mathrm{C}$.

Figure 6 shows that necking between the powder particles is initiated at a sintering temperature of 900 ㅇ C (Figure 6 a), which agrees with the results of the dilatometric study (Figure 3), where the onset temperature is observed to be approximately $810^{\circ} \mathrm{C}$ (Table 3). However, many more interparticle boundaries are still visible compared with the Ti-6Al-4V alloy sintered at 900ㄷ (Figure $4 \mathrm{a}$ ). This is mainly due to the lower compacting pressure used for the Ti-3Al-2.5V powder blend, which results in a greater porosity (lower green density) and delays the sintering of the powder particles (Figure 3). Consequently, the pore structure is primarily constituted by angular and interconnected pores. Moreover, larger but irregularly shaped pores can be found near the master alloy particles due to the diffusion of the alloying elements, which exhibit a diffusion rate different from that of titanium and, therefore, generate Kirkendall porosity. As for the Ti-6Al-4V alloy, the microstructure of the specimens sintered at $900^{\circ} \mathrm{C}$ is not homogeneous, which is because this sintering temperature is lower than the beta transus and is not high enough to supply an amount of thermal energy sufficient to guarantee the complete diffusion of the alloying elements.

The variation in the percentage of the alloying elements was analysed by BSE-SEM, and an example of one of the zones where diffusion takes place in the specimens sintered at $900^{\circ} \mathrm{C}$ is shown in Figure 7. 
The results of the EDS analysis of the zone where the diffusion of the alloying elements takes place in the Ti-3Al-2.5V powder blend specimens during sintering at $900^{\circ} \mathrm{C}$ (Figure 7) are similar to those of the Ti-6Al-4V powder used to obtain the blend because aluminium diffuses more quickly than titanium, and vanadium is present only in isolated zones composed of lamellae.

In general, the microstructural evolution of the elementally blended Ti-3Al-2.5V alloy can be summarised as follows:

- At $1000^{\circ} \mathrm{C}$, the composition seems to be homogeneous, but there are still some small darker zones where the concentration of aluminium is somewhat higher and the porosity is mostly irregular due to the joining of the pores located at the interparticle boundaries;

- At $1100^{\circ} \mathrm{C}$, the alloy is completely homogeneous and the porosity is much less interconnected and becomes spherical;

- Starting from 1200 드, the pores structure is mainly composed of spherical and isolated pores, the mean alpha grain size increases with the temperature and the thickness of the beta lamellae becomes thinner.

The EDS analysis of the specimens made from the elementally blended Ti-3Al-2.5V powder sintered over the temperature range from $1100^{\circ} \mathrm{C}$ to $1400^{\circ} \mathrm{C}$ indicates that the composition is homogeneous and can be denoted as 94.1Ti-3.6Al-2.3V. The atomic composition of the alpha and beta phase is shown in Table 5.

Once again, during the EDS analysis of the alpha and beta phases, fluctuations in the percentage of the alloying elements (Table 5) were detected, especially in the composition of the beta lamellae due to the magnitude of the areas analysed. As observed for the Ti-6Al-4V alloy, the amount of vanadium dissolved in the alpha phase was lower than the maximum solubility of 3 at.\% (Murray, 1987). The compositions of the two microconstituents in atomic percentage are 92.1Ti-7.1Al-0.8V (alpha) and 89.6Ti-4.7Al-6.2 V (beta), respectively.

\section{$\underline{3.6 \mathrm{XRD} \text { analysis of the sintered materials }}$}

Figure 8 shows an XRD pattern that is representative of the sintered samples, particularly those processed at $900^{\circ} \mathrm{C}, 1100^{\circ} \mathrm{C}$ and $1300^{\circ} \mathrm{C}$. 
The phases detected in the specimens sintered at 900 ㄷ (Figure 8) are titanium alpha, titanium beta and $\mathrm{Al}_{2} \mathrm{~V}_{3}$, which had already been detected in the starting powder (Figure 1). The XRD pattern of the specimens sintered at $1100^{\circ} \mathrm{C}$ confirms the results of the microstructural evolution and of the EDS analysis, indicating that the distribution of the alloying elements is homogeneous because no $\mathrm{Al}_{2} \mathrm{~V}_{3}$ peaks were found. No significant difference can be observed in the XRD patterns of the specimens sintered at $1300^{\circ} \mathrm{C}$ (Figure 8 ) in comparison to those of the samples processed at $1100^{\circ} \mathrm{C}$.

\section{$\underline{3.7 \text { Density of sintered materials }}$}

A comparison of the density of the Ti-6Al-4V and Ti-3Al-2.5V specimens as a function of the sintering temperature is illustrated in Figure 9.

Figure 9 shows that the densities of both titanium alloys studied increase asymptotically with the sintering temperature, reaching a maximum value at $1300^{\circ} \mathrm{C}$, and then stabilise. This result agrees with the microstructural trend shown in Figure 4 and Figure 6 for Ti-6Al-4V and Ti-3Al-2.5V, respectively, because the greatest extent of interparticle necking and densification of the material takes place over the $900-1300 \circ \mathrm{C}$ temperature range. Starting from $1300^{\circ} \mathrm{C}$, the thermal energy is spent for pore coarsening and grain growth, especially at $1400{ }^{\circ} \mathrm{C}$, which is why the density increases to a lesser degree. The corresponding relative density values shown in Figure 9, which vary from approximately $83 \%$ to $95 \%$ of the theoretical density, are similar to those found for other titanium alloys using the same processing route (Bolzoni et al., 2012c).

\subsection{Mechanical characterisation}

Figure 10 shows representative examples of the load-deflection curves obtained when testing the sintered samples by means of three-point bending tests.

The load-deflection curves shown in Figure 10 show that, with the density values obtained (Figure 9), the Ti-6Al-4V and Ti-3Al-2.5V alloy reach a similar flexural modulus because the curves of the two materials overlap in the region that corresponds to the elastic deformation of the samples. Furthermore, it can also be observed that the samples of both alloys behave as brittle materials and fail without any appreciable plastic deformation when sintered at low temperature $\left(900^{\circ} \mathrm{C}\right)$ or at high 
temperature $\left(1400^{\circ} \mathrm{C}\right)$, whereas the specimens undergo plastic deformation before fracture when sintered at an intermediate temperature such as $1100^{\circ} \mathrm{C}$. For the samples processed at low temperature (Figure 10 a), the fragile behaviour is mainly because the sintering of the powder has just begun, as described previously, which corresponds to a inhomogeneous microstructure and to a pore structure composed of irregular and interconnected pores. Therefore, the samples present intergranular fracture, which is exclusively due to grain-boundary separation (intercrystalline fracture), as shown in the right part of Figure $10 \mathrm{a}$. On the other hand, the samples sintered at high temperature (Figure $10 \mathrm{c}$ ) fail due to transcrystalline fracture, the typical cleavage fracture mode of metals with an H.C.P. lattice, where river marking can be clearly distinguished within the grains that form the microstructure. The failure of the specimens sintered at an intermediate temperature (Figure $10 \mathrm{~b}$ ) is still mainly due to intercrystalline fracture by grain-boundary separation, but the formation of river marking can already be observed within some grains, indicating that there is a component of transcrystalline fracture. This switching from intercrystalline to transcrystalline fracture is correlated with the homogenisation of the alloying elements throughout the microstructure and particularly with the evolution of the pore structure because at $1100 \circ \mathrm{C}$ the pores are mostly spherical and isolated.

Because the formula specified in the ASTM B528 standard for the calculation of transverse rupture strength by means of the thee-point bending test can be applied only for relatively brittle materials and, as shown, the Ti-6Al-4V and Ti-3Al-2.5V samples deform plastically, it the yield strength values were considered; these are plotted as a function of the sintering temperature in Figure 11.

As shown in Figure 11, the yield strength of the sintered specimens increases with the sintering temperature up to a maximum value, which coincides with the processing temperature of 1200 ㅇ $\mathrm{C}$ for the Ti-6Al-4V alloy and 1300 o C for the Ti-3Al-2.5V alloy, and then decreases. Moreover, the strength values obtained for the two materials are similar when using low $(900-1000 \circ)$ and high $(1400 \circ \mathrm{C})$ sintering temperatures, while at intermediate temperatures the Ti-6Al-4V alloy shows higher yield strength. This mechanical behaviour is due to the compromise between the microstructural evolution (homogenisation of the alloying elements), the amount, shape and distribution of the residual porosity and the relative amount and characteristics of the two microstructural features ( $\alpha$ grains and $\alpha+\beta$ lamellae). The yield strength values shown in Figure 11 are always higher than the yield strength of the $\alpha$ $+\beta$ Ti-6Al-7Nb alloy obtained by master alloy addition (Bolzoni et al., 2012c) and the flexural strength specified for wrought Ti-6Al-4V medical devices (903-1090 MPa) (Henry, 2009) but comparable to that of vacuum hot-pressed materials (Bolzoni et al., 2012b; Bolzoni et al., 2012d). The higher strength of 
pressed and sintered components with respect to the wrought alloy, even though of the residual porosity, is due to the typical smaller grain size of powder metallurgy parts and to the higher interstitials content of the alloys studied. The average oxygen and nitrogen content of pressed and sintered Ti-6Al$4 \mathrm{~V}$ and Ti-3Al-2.5V samples, which was measured by means of inert gas fusion technique (LECO), is approximately $0.45 \mathrm{wt} . \%$ and $0.03 \mathrm{wt} . \%$, respectively. The amount of oxygen dissolved results to be slightly higher than the double of the amount of oxygen specified for the wrought materials (0.20 wt.\%) (Boyer et al., 1998) and it is well-known that, for titanium alloys, the greater the interstitials content, the stronger and more fragile the material (Jaffee and Campbell, 1949; Jaffee et al., 1950; Finlay and Snyder, 1950).

The variation in the Vickers hardness values measured for sintered samples versus the sintering temperature is illustrated in Figure 12.

Figure 12 shows that the hardness of both the P/M Ti-6Al-4V and Ti-3Al-2.5V samples increases continuously with the sintering temperature due to the reduction in the residual porosity, equivalent to an increment in the density (Figure 9), reaching maximum values of approximately $350 \mathrm{HV}$. Moreover, it can also be appreciated that the pressed and sintered samples equalise the hardness of the respective wrought alloys starting at a sintering temperature of approximately $1300 \circ \mathrm{C}$, despite the residual porosity left by the sintering step. This is most likely due to the normally finer microstructure typical of $\mathrm{P} / \mathrm{M}$ materials with respect to that of wrought alloys and the higher amount of interstitials dissolved (Table 1), which increases the hardness of titanium and its alloys (Jaffee and Campbell, 1949; Jaffee et al., 1950; Finlay and Snyder, 1950). 


\section{Conclusions}

The following conclusions can be drawn from the results of the characterisation of the prealloyed Ti-6Al$4 \mathrm{~V}$ and elementally blended Ti-3Al-2.5V powders and their microstructural evolution with the sintering temperature when processed by cold uniaxial pressing and sintering:

- The titanium powder metallurgy industry needs more reliable angular HDH prealloyed powders that can be used to obtain final products or that can be employed as master alloys to add the alloying elements desired;

- By using a prealloyed powder, the interaction of elemental titanium with elemental aluminium, which generates intermetallic $\mathrm{TiAl}_{3}$, is avoided;

- The conventional powder metallurgy route of pressing and sintering can be exploited for the fabrication of titanium products starting from irregular prealloyed powder or elementally blended powder using a master alloy;

- Various relative densities, between $83 \%$ and $95 \%$, pore structures and grain sizes can be obtained by selecting a proper sintering temperature, but when the alloying elements have to diffuse to homogenise the composition, a minimum temperature of $110^{\circ} \mathrm{C}$ should be selected;

- Higher flexural strength and hardness in comparison to the values specified for biomedical devices obtained by means of conventional metallurgy are obtained.

\section{Acknowledgements}

The authors would like to acknowledge the financial support of the Spanish Ministry of Science through the R\&D Projects MAT2009-14448-C02-02 and MAT2009-14547-C02-02, and the Regional Government of Madrid through the ESTRUMAT (S2009/MAT-1585) project.

\section{References}

Bolzoni, L., Ruiz-Navas, E. M, Neubauer, E., Gordo, E., 2012. Inductive Hot-pressing of Titanium and Titanium Alloy Powders. Materials Chemistry and Physics 131, 672-679. 
Bolzoni, L., Ruiz-Navas, E. M, Gordo, E., 2012. Vacuum Hot-Pressing of Ti-3Al-2.5V Alloy: Microstructural Evolution and Mechanical Properties. Materials Chemistry and Physics, (Under Review).

Bolzoni, L., Ruiz-Navas, E. M, Weissgaeber, T., Kieback, B., Gordo, E., 2012. Mechanical Behaviour of Pressed and Sintered CP Ti and Ti-6Al-7Nb Alloy Obtained from Master Alloy Addition Powder. Journal of Mechanical Behavior of Biomedical Materials, (Under Review).

Bolzoni, L., Ruiz-Navas, E. M, Montealegre Meléndez, I., Gordo, E., 2012. Microstructural Evolution and Mechanical Properties of the Ti-6Al-4V Alloy Produced by Vacuum Hot-pressing. Materials Science and Engineering A 546, 189-197.

Böhm and Kieback, 1998. Investigation of Swelling Behaviour of Ti-Al Elemental Powder Mixtures during Reaction Sintering. Zeitschrift für Metallkunde 89, 90-95.

Boyer, R., Welsch, G., Collings, E. W., 1998. Materials Properties Handbook: Titanium Alloys, Second ed. ASM-International, Ed. Ohio, USA.

Dewidar, M. M., Yoon, H-C., Lim, J. K., 2006. Mechanical properties of metals for biomedical applications using powder metallurgy process: A review. Metals and Materials International 12, 193-206.

Finlay W. L. and Snyder, J. A., 1950. Effects of Three Interstitial Solutes (Nitrogen, Oxygen and Carbon) on the Mechanical Properties of High-purity Alpha Titanium. Journal of Metals 188, 277-286.

Henry D., 2009. Materials and Coatings for Medical Devices: Cardiovascular. Ohio, USA, ASM International, 151-186.

Ivasishin, O. M., 2005. Cost-effective Manufacturing of Titanium Parts with Powder Metallurgy Approach. Materials Forum 29, 1-8.

Jaffee, R. I. and Campbell, I. E., 1949. The Effect of Oxygen, Nitrogen and Hydrogen on lodide Refined Titanium. Transactions of the American Institute of Mining and Metallurgical Engineers 185, 646654.

Jaffee, R. I., Ogden, H. R., Maykuth, D. J., 1950. Alloys of Titanium with Carbon, Oxygen and Nitrogen. Transactions of the American Institute of Mining and Metallurgical Engineers 188, 1261-1266.

Leyens, C. and Peters, M., 2003. Titanium and Titanium Alloys. Fundamentals and Applications. Köln, Germany, Wiley-VCH, 1-497. 
Lütjering, G., Williams, J. C., 2003. Titanium: Engineering Materials and Processes, First ed. Manchester, UK, Springer, 1-356.

Murray, J. L., 1987. Phase Diagrams of Binary Titanium Alloys, First ed, ASM International, 1-345.

Niinomi, M., 2002. Recent metallic materials for biomedical applications, Metallurgical and Materials Transactions A 33, 477-486.

Parsons, L., Bruce, J., Lane, J., Froes, F. H., 1984. Titanium P/M Comes of Age. Metal Progress 126, 83-94. 


\section{List of Figure Captions}

Figure 1. Representative X-ray diffraction (XRD) pattern of the processed powders.

Figure 2. DTA heating curves for prealloyed Ti-6Al-4V powder and the elementally blended Ti-3Al-2.5V powder.

Figure 3. Comparison of dilatometric curves for the prealloyed Ti-6Al-4V powder and the elementally blended Ti-3Al-2.5V powder.

Figure 4. Microstructural evolution of the prealloyed Ti-6Al-4V powder sintered under high vacuum: a) $900^{\circ} \mathrm{C}$, b) $1000^{\circ} \mathrm{C}$, c) $1100^{\circ} \mathrm{C}$, d) $1200^{\circ} \mathrm{C}$, e) $1300^{\circ} \mathrm{C}$ and f) $1400^{\circ} \mathrm{C}$.

Figure 5. Details of the diffusion of the alloy elements in the prealloyed Ti-6Al-4V powder and relative change in EDS composition (distance from position: $10 \mu \mathrm{m}$ ).

Figure 6. Microstructural evolution of the elementally blended Ti-3Al-2.5V powder sintered under high vacuum at sintering temperatures of a) $900 \circ \mathrm{C}$, b) $1000^{\circ} \mathrm{C}$, c) $1100 \circ \mathrm{C}$, d) $1200 \circ \mathrm{C}$, e) $1300 \circ \mathrm{C}$ and f) 1400 ㅇ․

Figure 7. Details of the diffusion of the alloy elements in the elementally blended Ti-3Al-2.5V powder and relative change in EDS composition (distance from position: $10 \mu \mathrm{m}$ ).

Figure 8. Representative XRD patterns of samples processed at different sintering temperatures. 
Figure 9. Variation in density with sintering temperature for prealloyed Ti-6Al-4V and elementally blended Ti-3Al-2.5V specimens obtained by pressing and sintering.

Figure 10. Representative load-deflection curves and relative fracture surface of Ti-6Al-4V and Ti-3Al$2.5 \mathrm{~V}$ samples sintered at a) $900^{\circ} \mathrm{C}$, b) $1100^{\circ} \mathrm{C}$ and c) $1400^{\circ} \mathrm{C}$.

Figure 11. Yield strength, determined by three-point bending tests, as a function of the sintering temperature for prealloyed Ti-6AI-4V and elementally blended Ti-3Al-2.5V samples.

Figure 12. Vickers hardness as a function of the sintering temperature for prealloyed Ti-6Al-4V and elementally blended Ti-3Al-2.5V samples.

\section{List of Tables}

Table 1. Characteristics of the starting powders considered in this study (supplier specifications).

Table 2. Onset temperature, top of the peak and nominal beta transus for the Ti-6Al-4V and Ti-3Al-2.5V titanium alloys. 
Table 3. Maximum shrinkage and onset temperature determined by the dilatometric analysis of prealloyed Ti-6Al-4V powder and elementally blended Ti-3Al-2.5V powder.

Table 4. EDS chemical composition of the alpha and the beta phase of the prealloyed Ti-6Al-4V alloy as a function of the sintering temperature.

Table 5. EDS chemical composition of the alpha and the beta phase of the elementally blended Ti-3Al$2.5 \mathrm{~V}$ alloy as a function of the sintering temperature.

Table 1. Characteristics of the starting powders considered in this study (supplier specifications).

\begin{tabular}{|c|c|c|}
\hline Feature & Ti-6Al-4V & Elemental Ti \\
\hline \hline Mean Particle size $(\mu \mathrm{m})$ & 32.88 & 37.59 \\
\hline Particle morphology & angular & angular \\
\hline Oxygen (wt. \%) & $\max 0.55$ & 0.31 \\
\hline Nitrogen (wt. \%) & $\max 0.30$ & 0.008 \\
\hline
\end{tabular}

Table 2. Onset temperature, top of the peak and nominal beta transus for the Ti-6Al-4V and Ti-3Al-2.5V titanium alloys.

\begin{tabular}{|c|c|c|c|c|}
\hline Alloy & Onset & $\begin{array}{c}\text { Top of the } \\
\text { peak }\left[{ }^{\circ} \mathrm{C}\right]\end{array}$ & Reaction & $\begin{array}{c}\text { Nominal beta } \\
\text { transus [으 }\end{array}$ \\
\hline $\begin{array}{c}\text { Elemental Ti (Bolzoni et } \\
\text { al., 2012c) }\end{array}$ & 875.51 & 904.71 & $\alpha \rightarrow \beta$ & $882 \pm 2$ \\
\hline Ti-6Al-4V & 906.47 & 959.89 & $\alpha \rightarrow \beta$ & $996 \pm 15$ \\
\hline
\end{tabular}




\begin{tabular}{|l|l|l|l|l|}
\hline Ti-3Al-2.5V & 887.26 & 928.00 & $\alpha \rightarrow \beta$ & $935 \pm 15$ \\
\hline
\end{tabular}

Table 3. Maximum shrinkage and onset temperature determined by the dilatometric analysis of prealloyed Ti-6Al-4V powder and elementally blended Ti-3Al-2.5V powder.

\begin{tabular}{|c|c|c|c|}
\hline Alloy & $\begin{array}{c}\text { Compaction } \\
\text { pressure [MPa] }\end{array}$ & $\begin{array}{c}\text { Maximum } \\
\text { shrinkage [\%] }\end{array}$ & $\begin{array}{c}\text { Onset } \\
\text { temperature [ }{ }^{\circ} \mathrm{C} \text { ] }\end{array}$ \\
\hline \hline Ti-6Al-4V & 400 & -13.47 & 723.3 \\
\hline Ti-3Al-2.5V & 300 & -13.72 & 810.8 \\
\hline
\end{tabular}

Table 4. EDS chemical composition of the alpha and the beta phase of the prealloyed Ti-6Al-4V alloy as a function of the sintering temperature.

\begin{tabular}{|c|c|c|c|c|c|c|}
\hline Temperature [ㅇ] & \multicolumn{3}{|c|}{ Composition $\alpha$-phase [at.\%] } & \multicolumn{2}{c|}{ Composition $\beta$-phase [at.\%] } \\
\hline & $\mathrm{Ti}$ & $\mathrm{Al}$ & $\mathrm{V}$ & $\mathrm{Ti}$ & $\mathrm{Al}$ & $\mathrm{V}$ \\
\hline \hline 1100 & 88.64 & 9.92 & 1.44 & 87.39 & 8.28 & 4.33 \\
\hline 1200 & 87.73 & 11.04 & 1.23 & 84.34 & 7.77 & 7.89 \\
\hline 1300 & 87.24 & 11.42 & 1.34 & 81.51 & 8.98 & 9.51 \\
\hline 1400 & 88.14 & 10.56 & 1.30 & 77.90 & 5.95 & 16.15 \\
\hline
\end{tabular}

Table 5. EDS chemical composition of the alpha and the beta phase of the elementally blended Ti-3Al$2.5 \mathrm{~V}$ alloy as a function of the sintering temperature.

\begin{tabular}{|l|l|l|}
\hline Temperature [으 & Composition $\boldsymbol{\alpha}$-phase [at.\%] & Composition $\boldsymbol{\beta}$-phase [at.\%] \\
\hline
\end{tabular}




\begin{tabular}{|c|c|c|c|c|c|c|}
\hline & $\mathrm{Ti}$ & $\mathrm{Al}$ & $\mathrm{V}$ & $\mathrm{Ti}$ & $\mathrm{Al}$ & $\mathrm{V}$ \\
\hline \hline 1100 & 92.72 & 6.77 & 0.51 & 89.84 & 3.59 & 6.57 \\
\hline 1200 & 92.24 & 6.88 & 0.88 & 89.97 & 5.95 & 4.08 \\
\hline 1300 & 92.17 & 7.01 & 0.82 & 89.76 & 4.55 & 5.69 \\
\hline 1400 & 91.34 & 7.61 & 1.05 & 86.96 & 4.63 & 8.41 \\
\hline
\end{tabular}

> Comparison of the prealloyed and blending elemental approach to fabricated titanium products. > Study of the homogenisation of the microstructure by diffusion processes. > Analysis of the microstructural evolution of the alloys with the processing temperature. $>$ Flexural properties of pressing and sintering Ti-6Al.4V and Ti-3Al-2.5V are measured. 


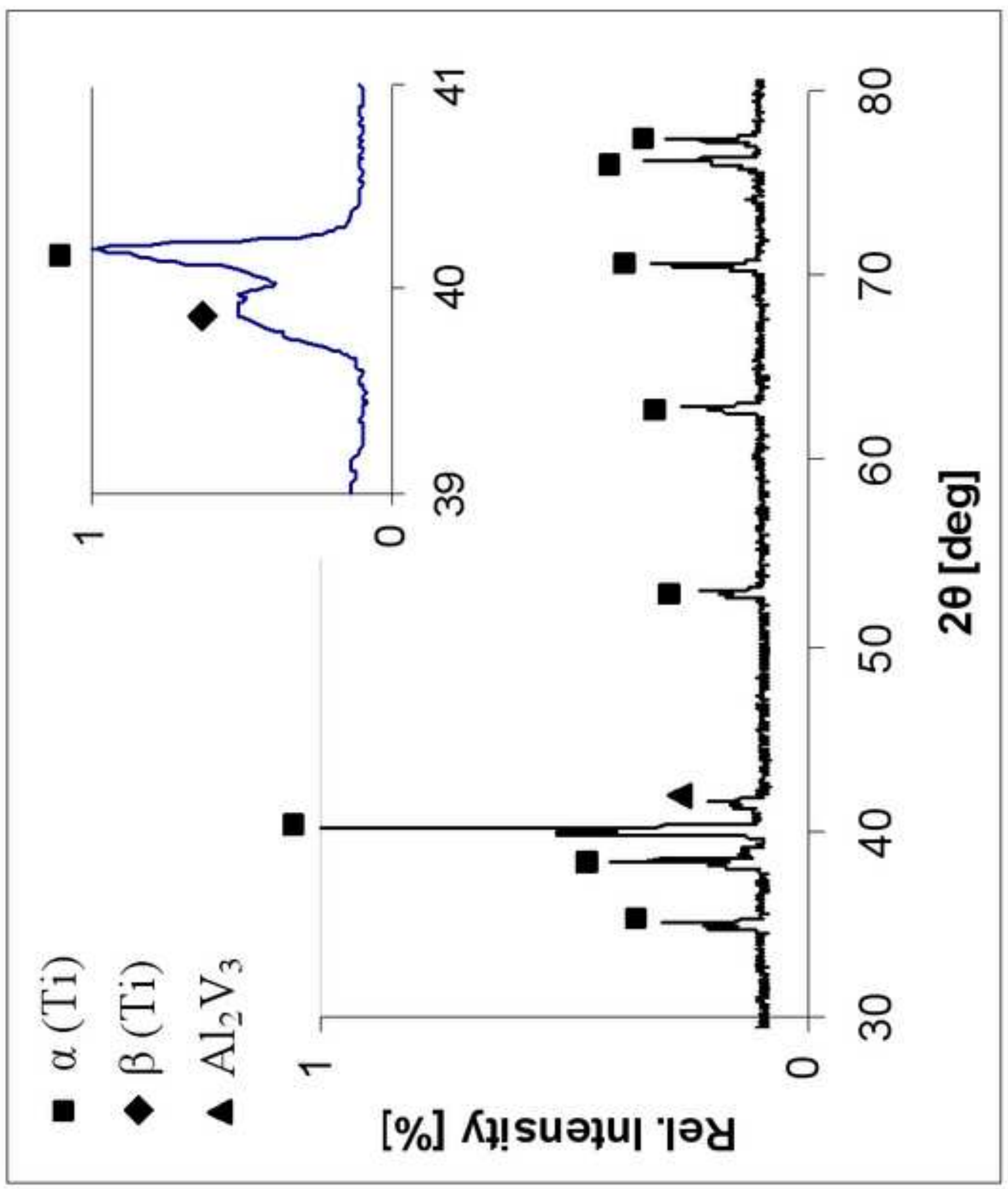




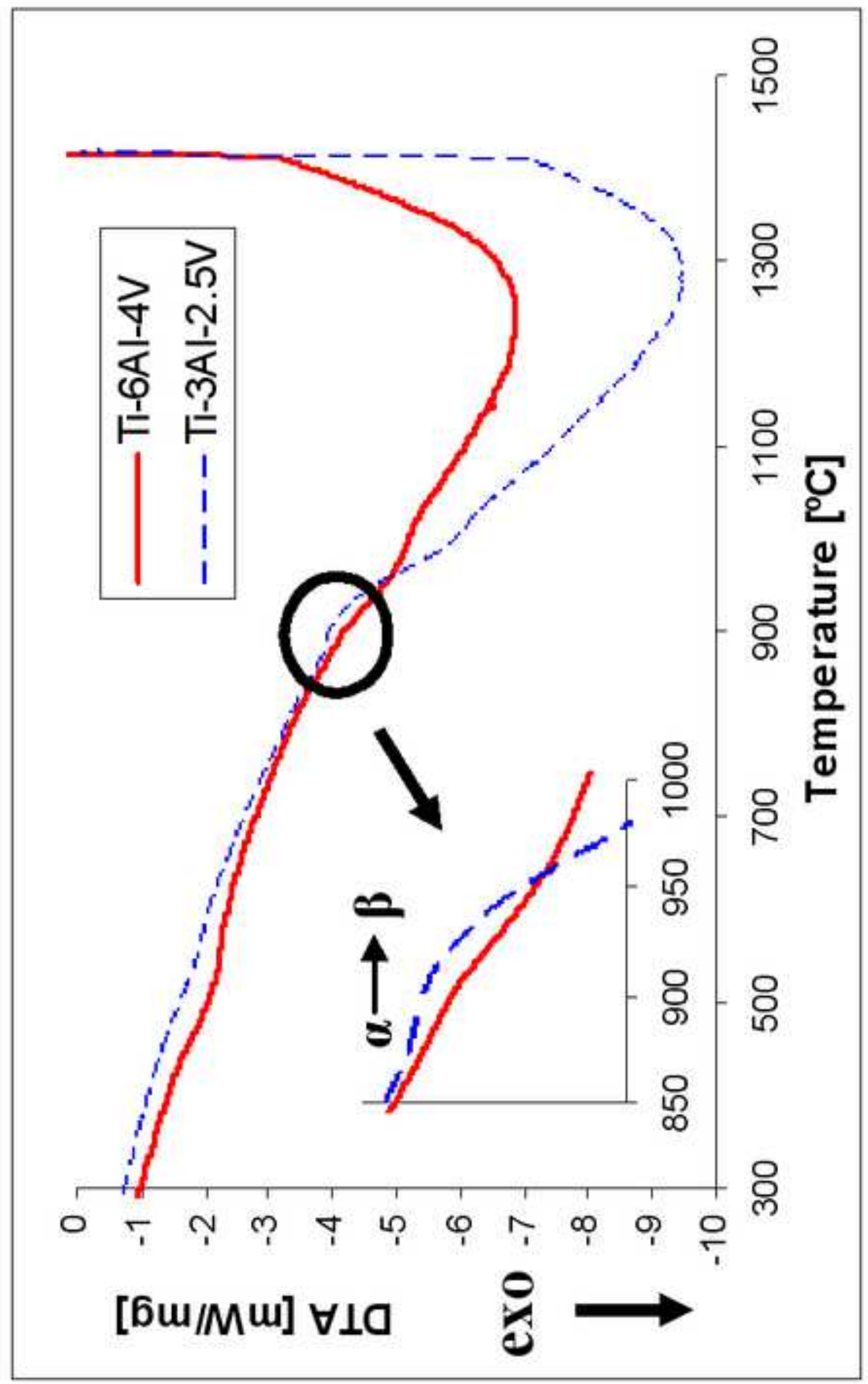




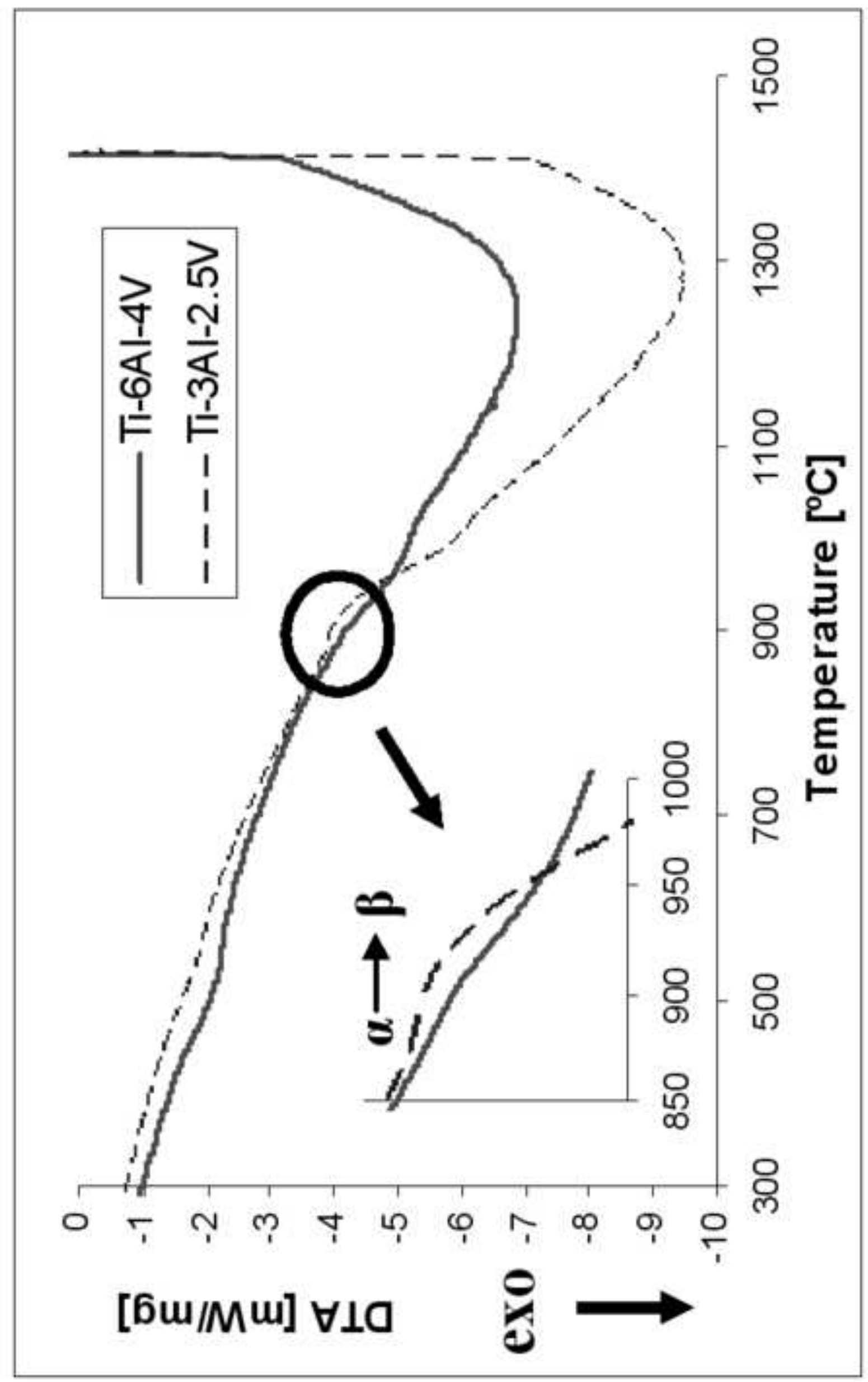




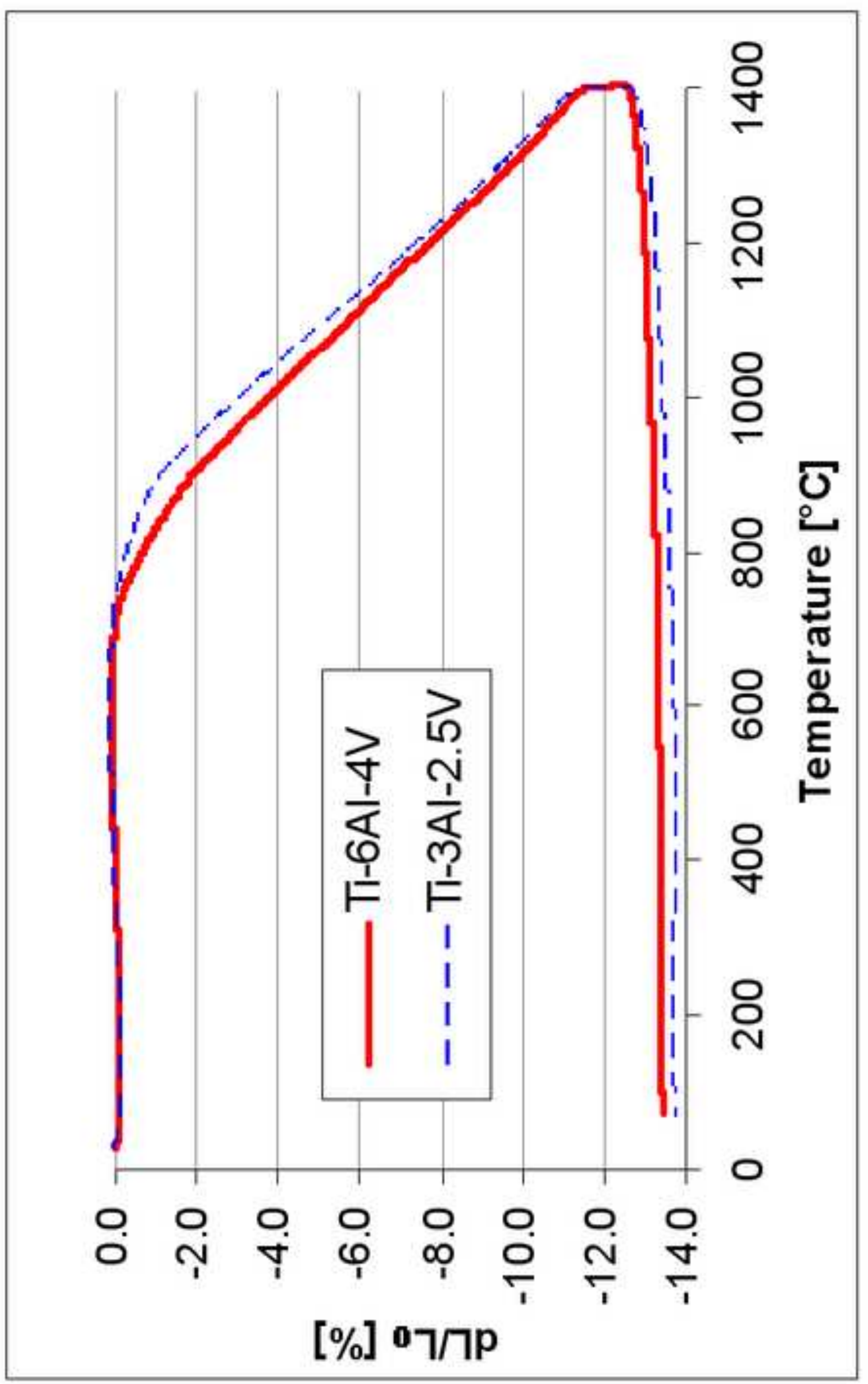

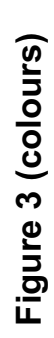




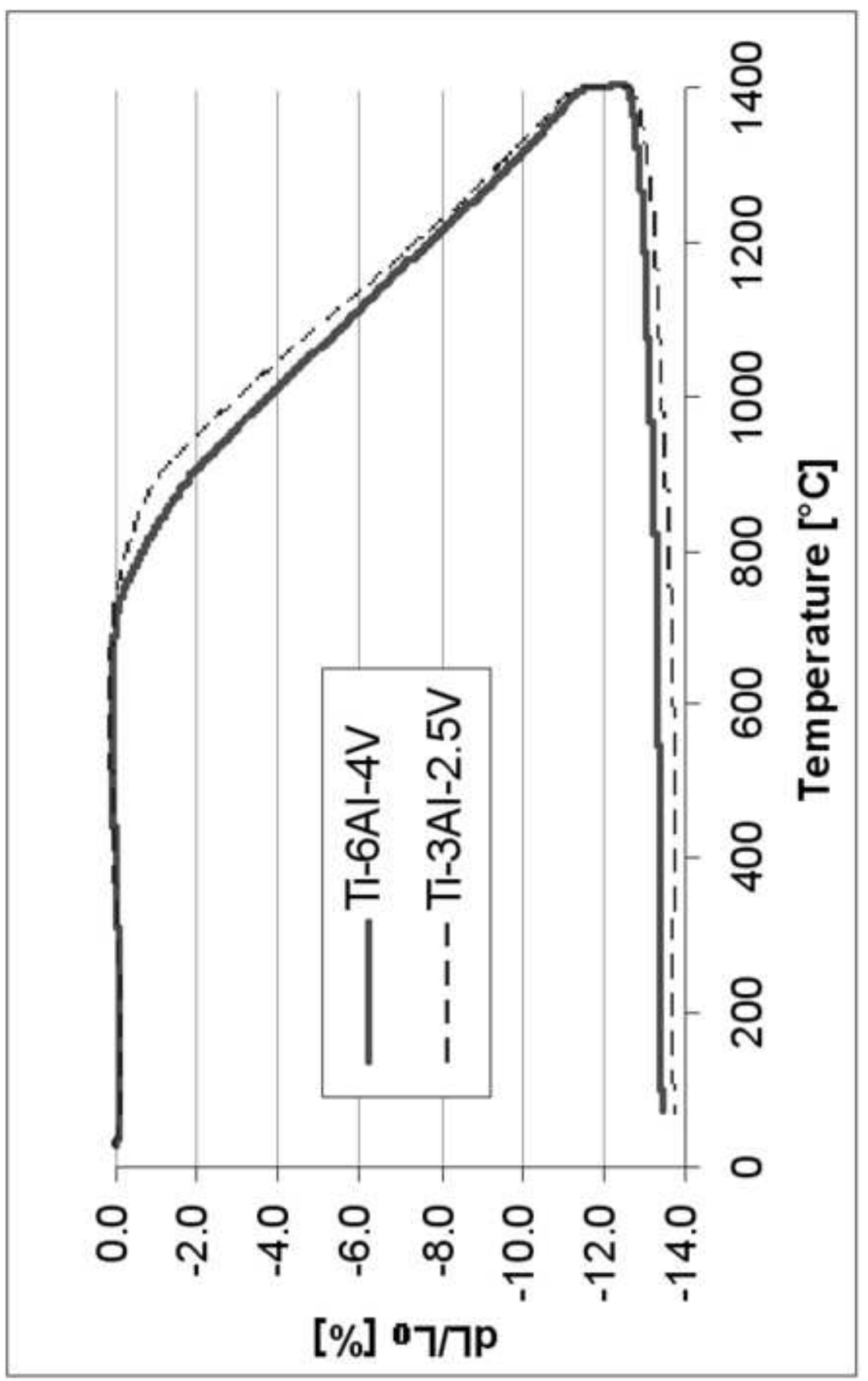




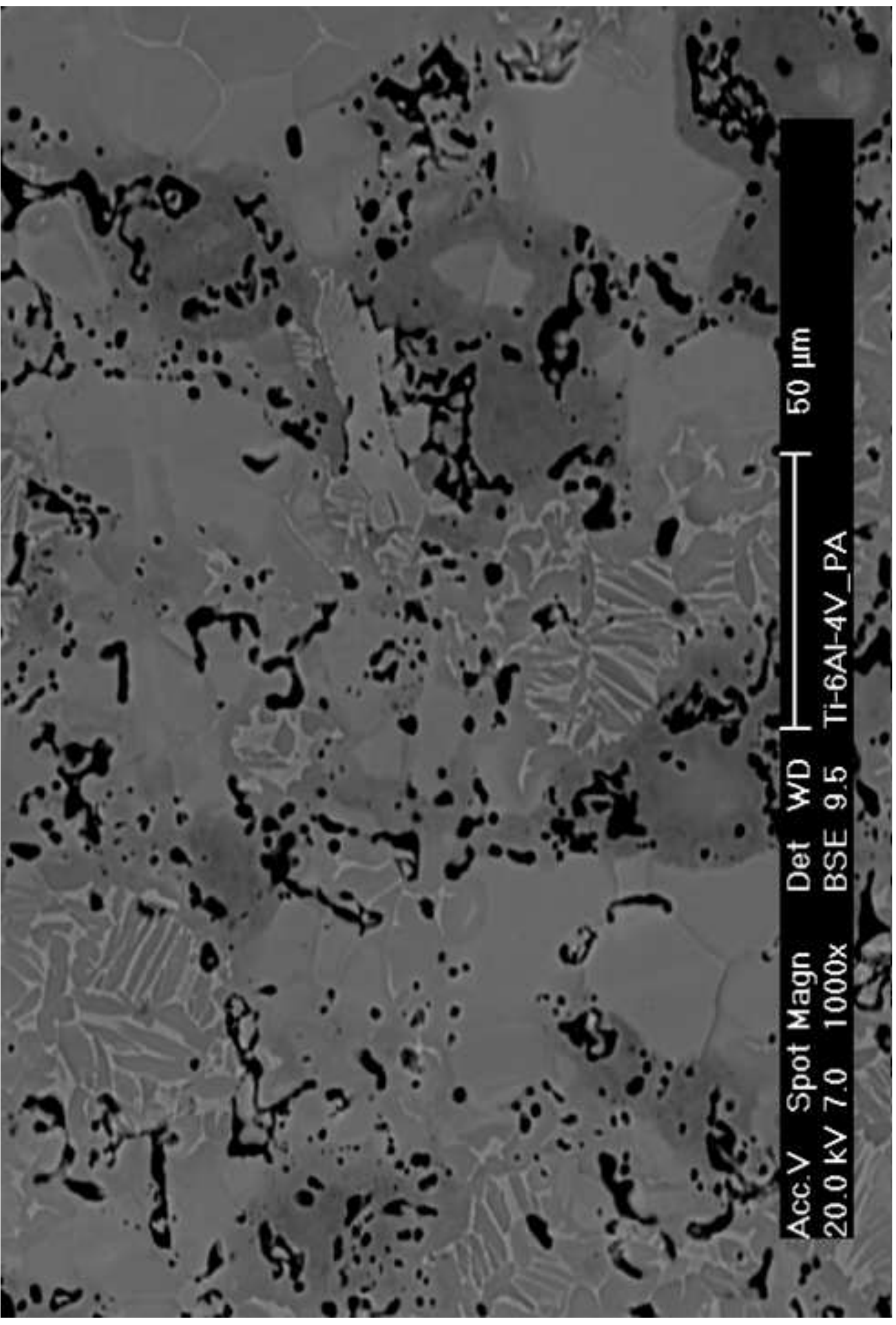




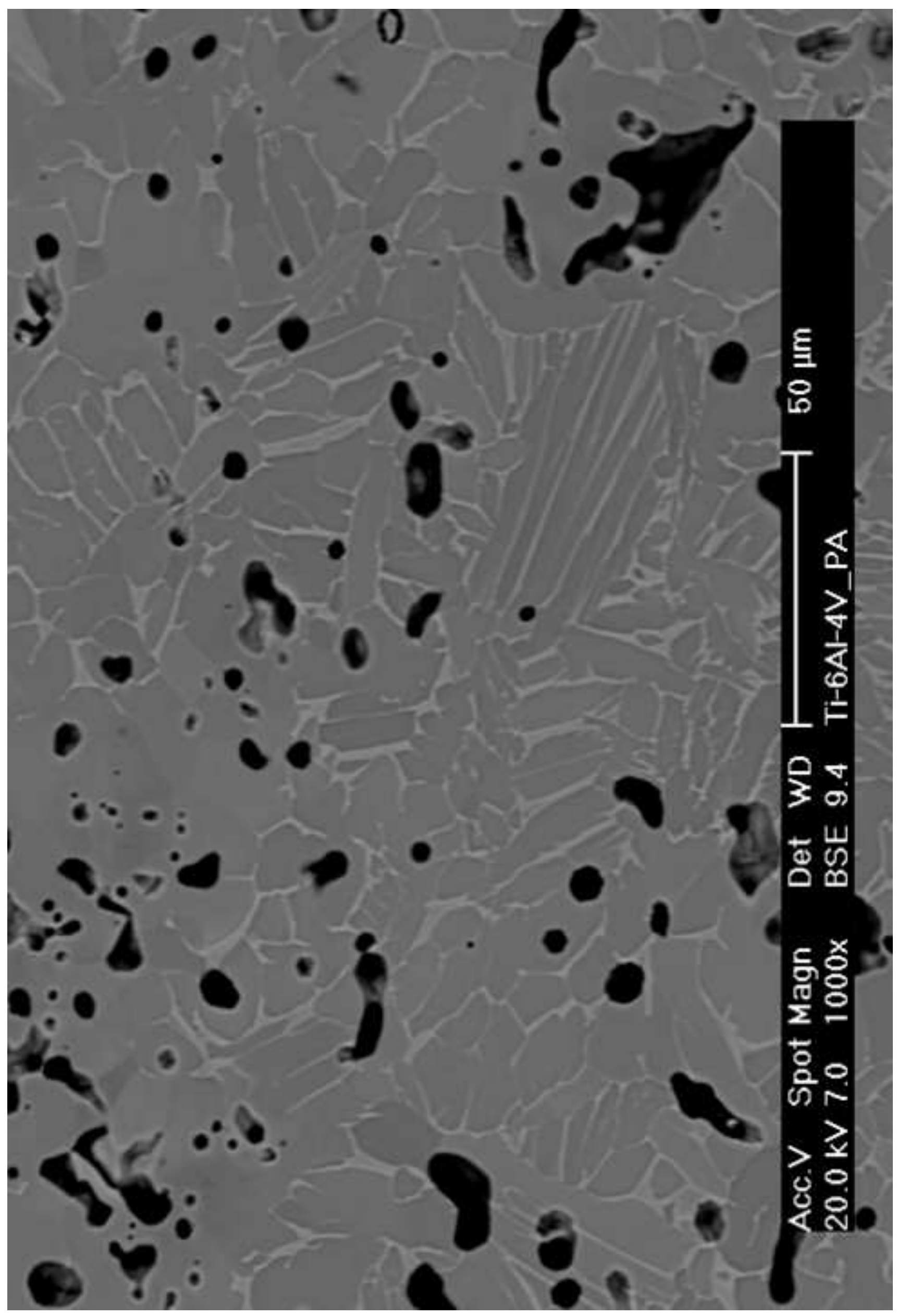




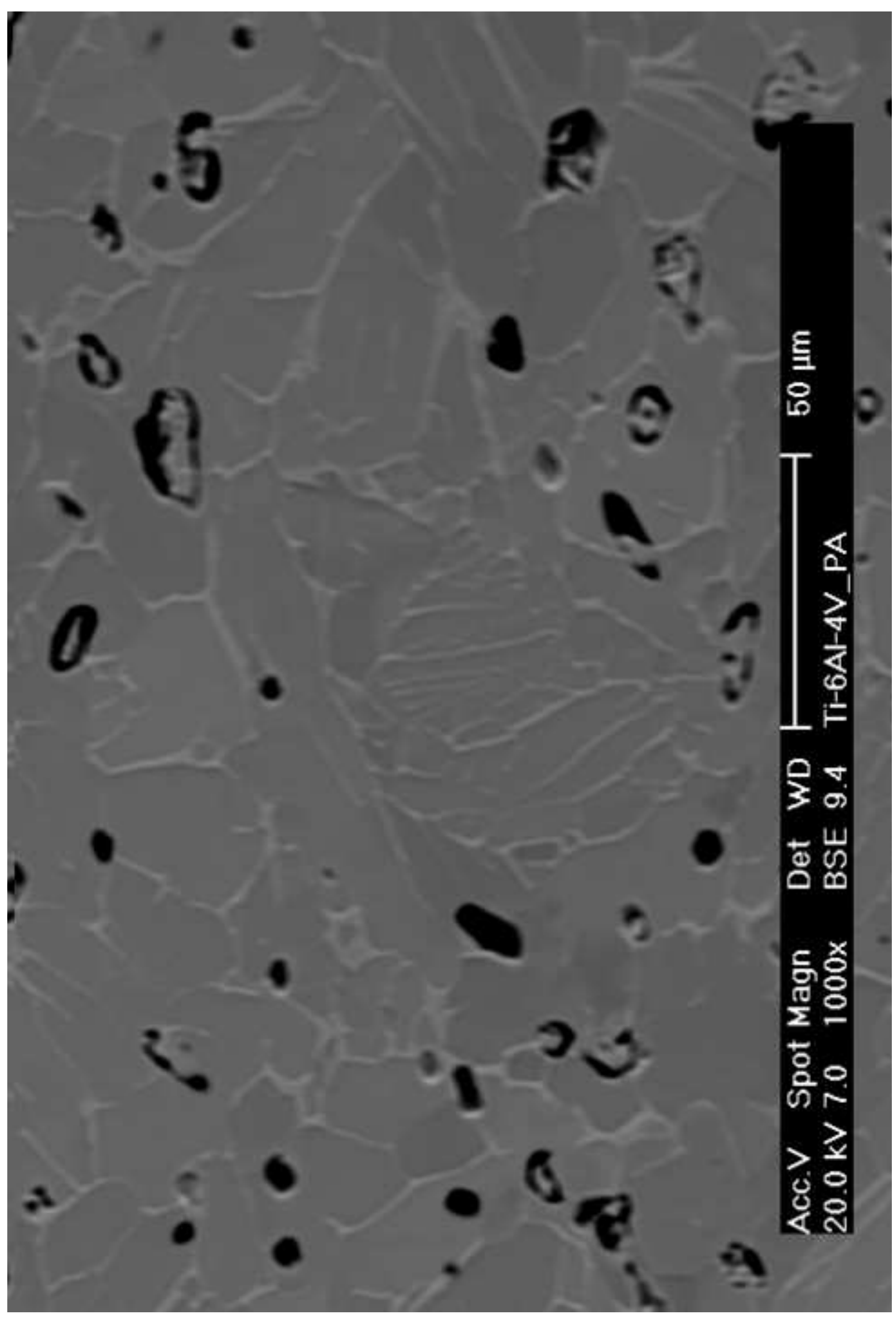




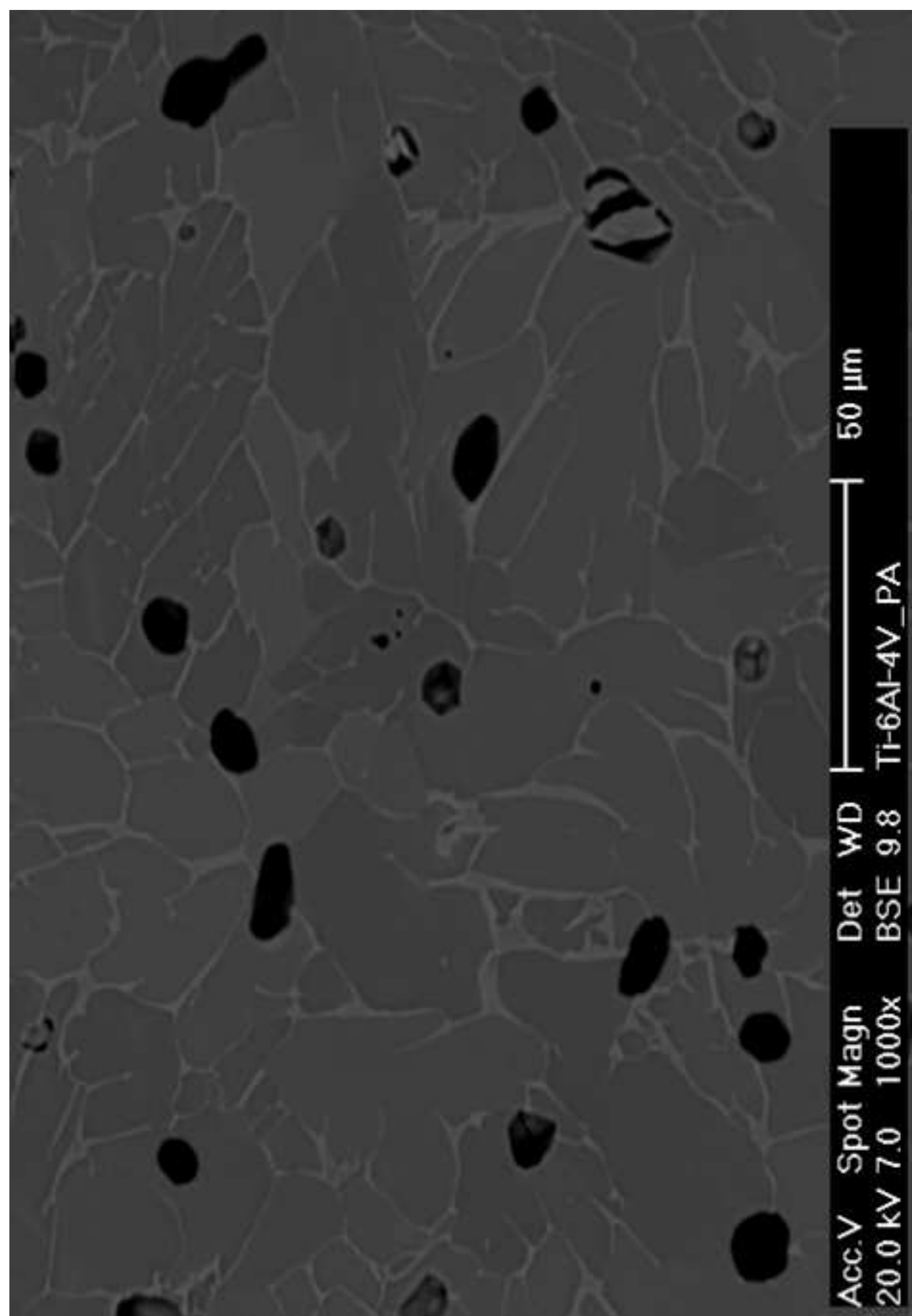




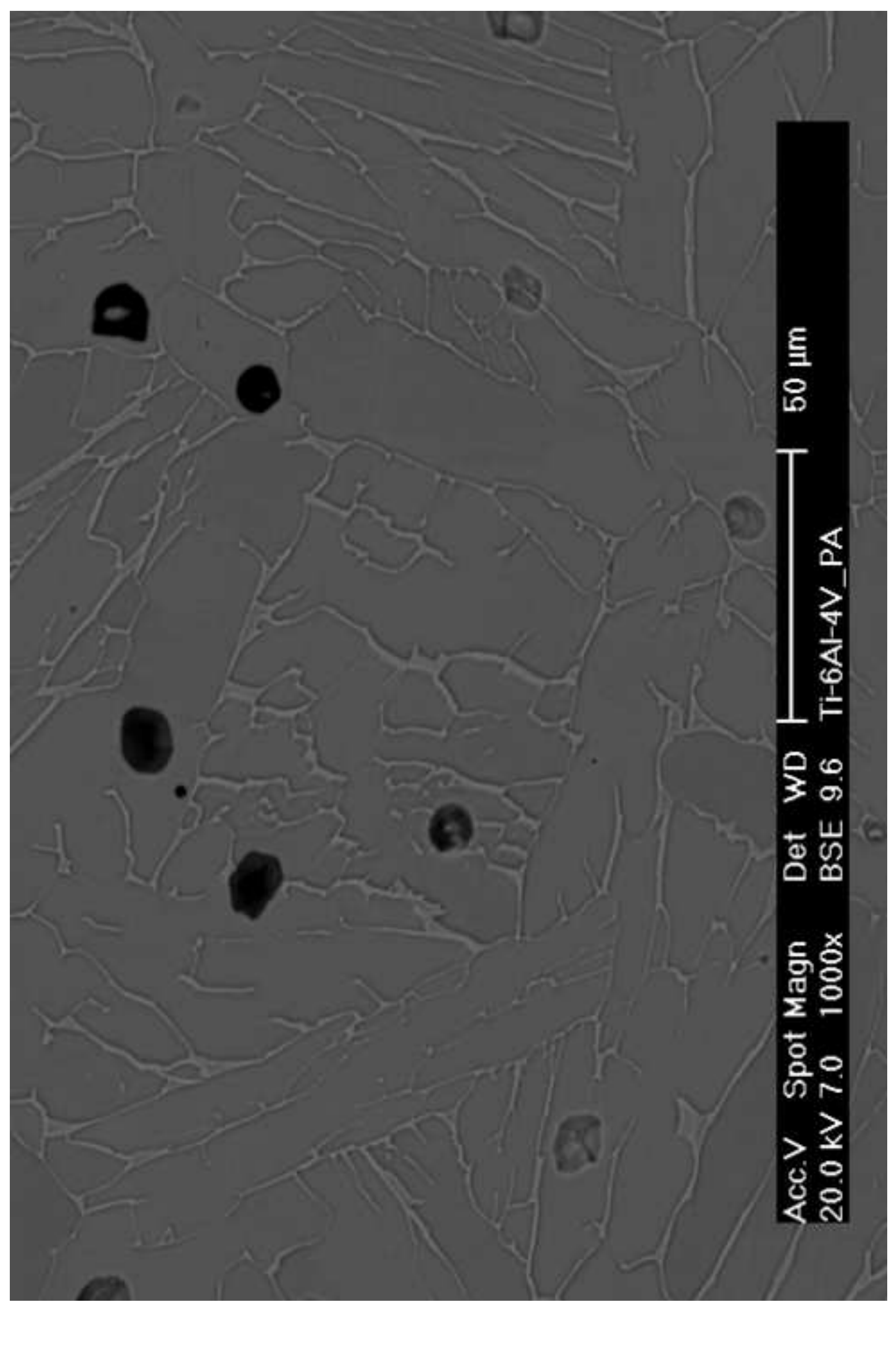




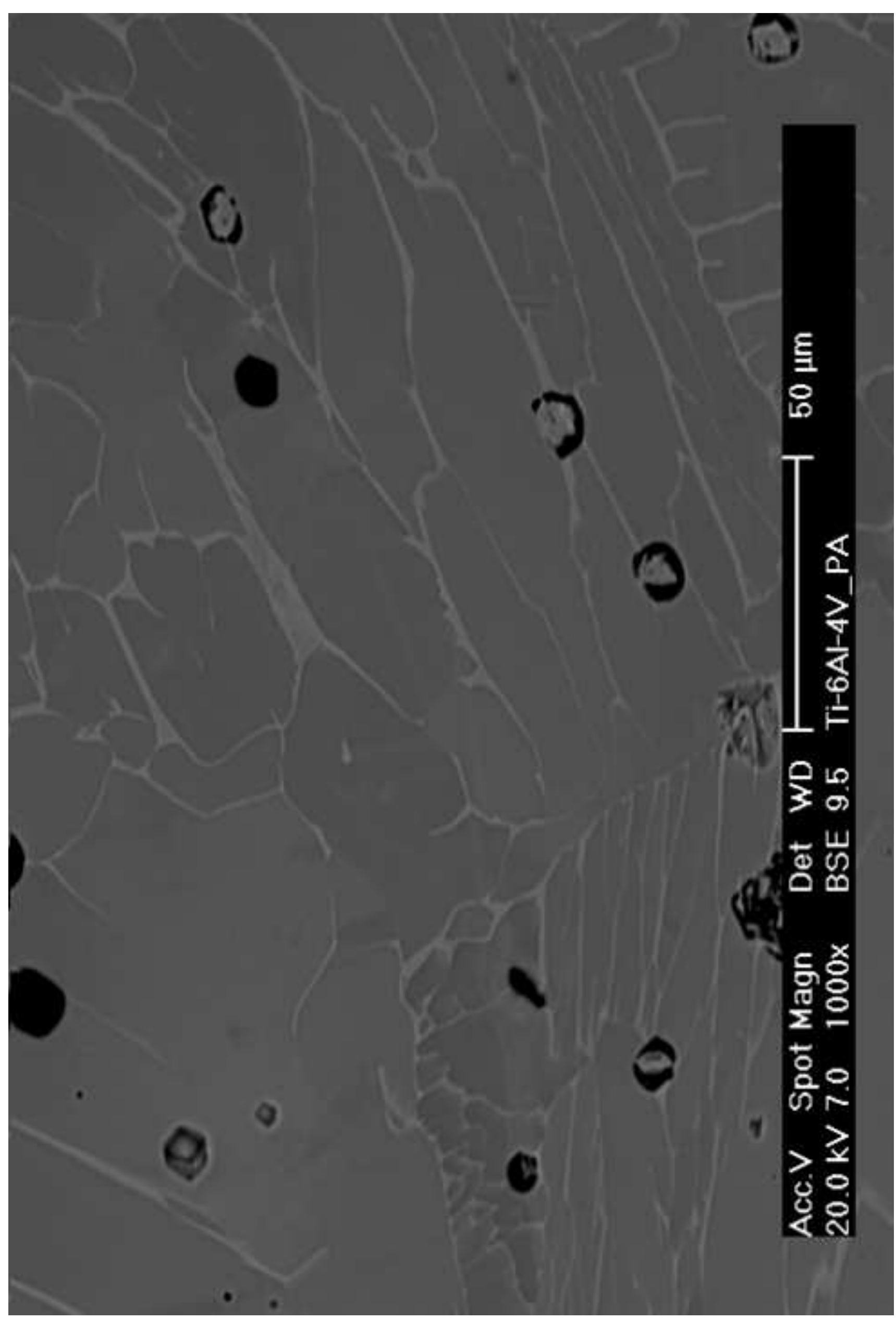

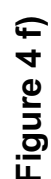




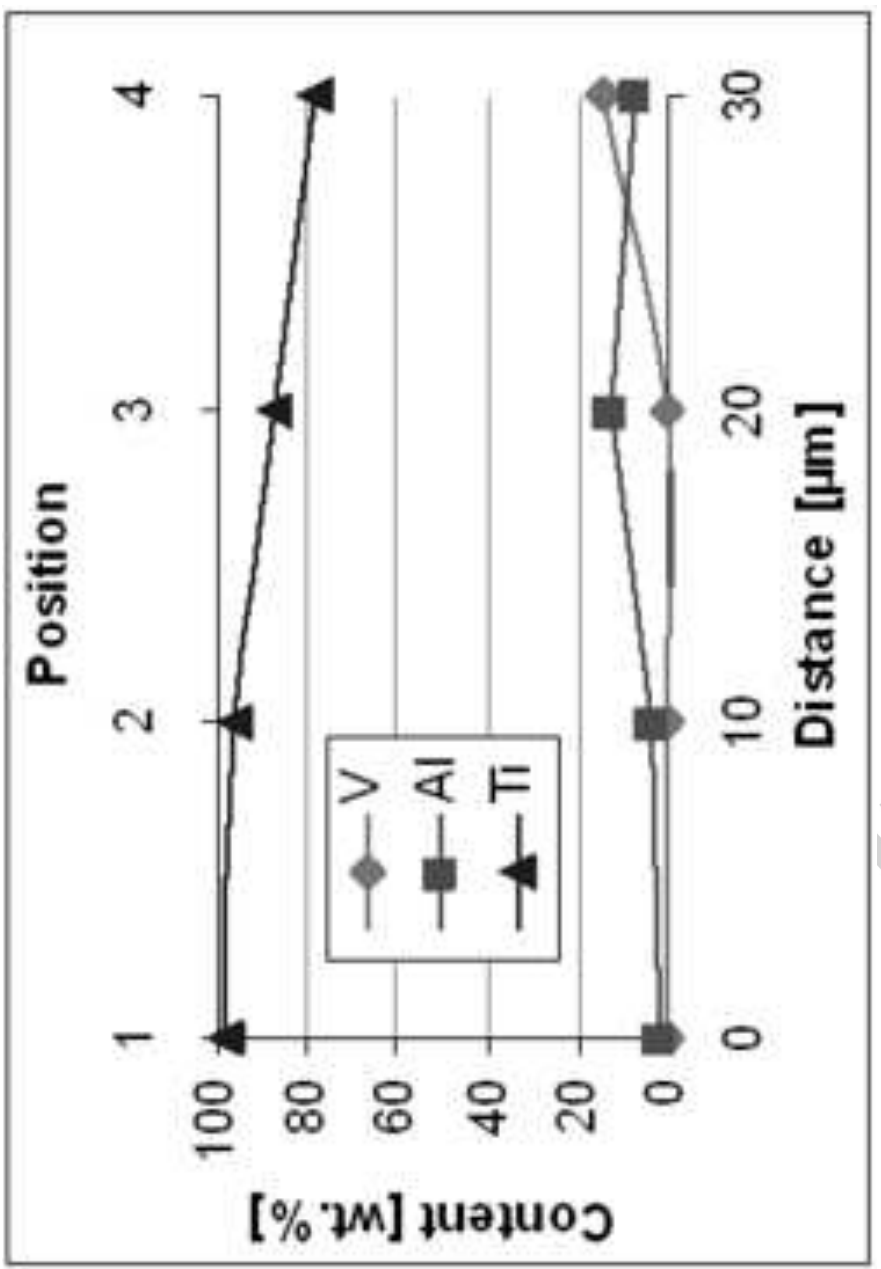

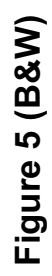

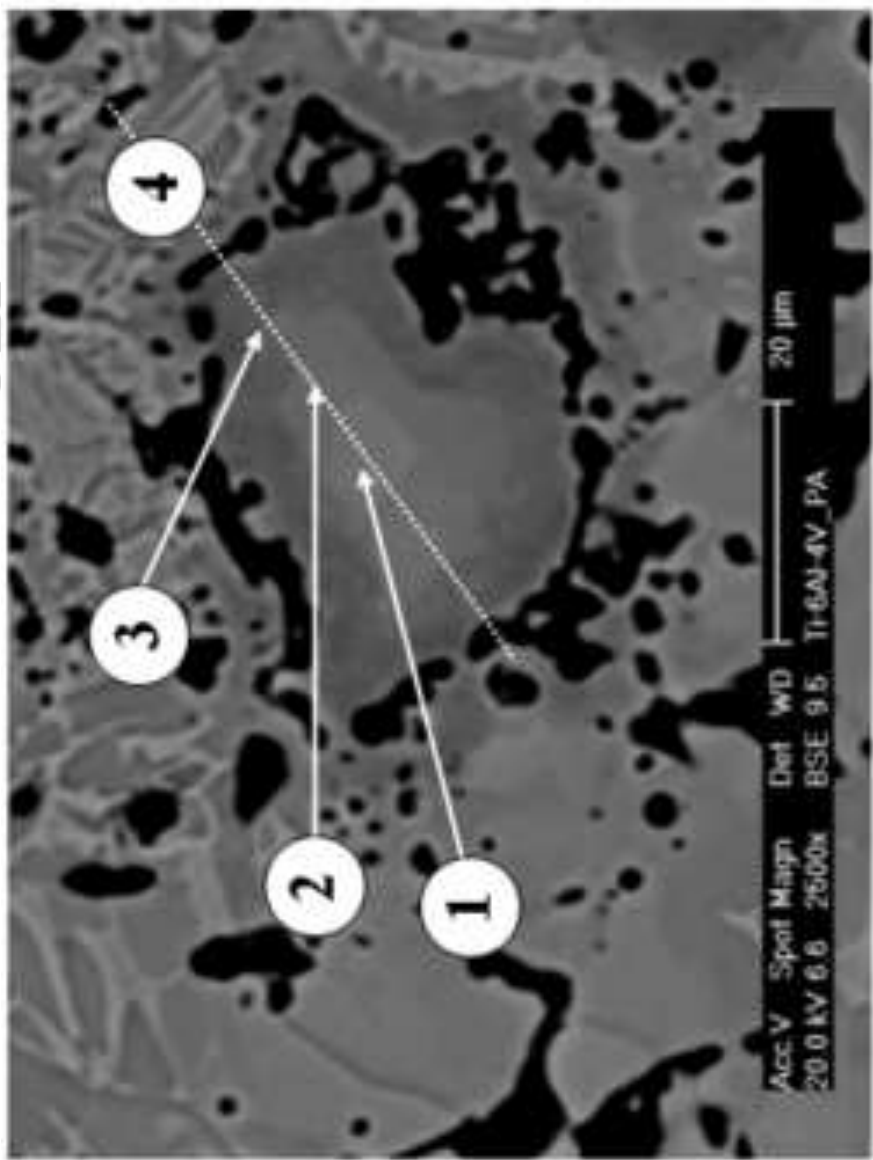




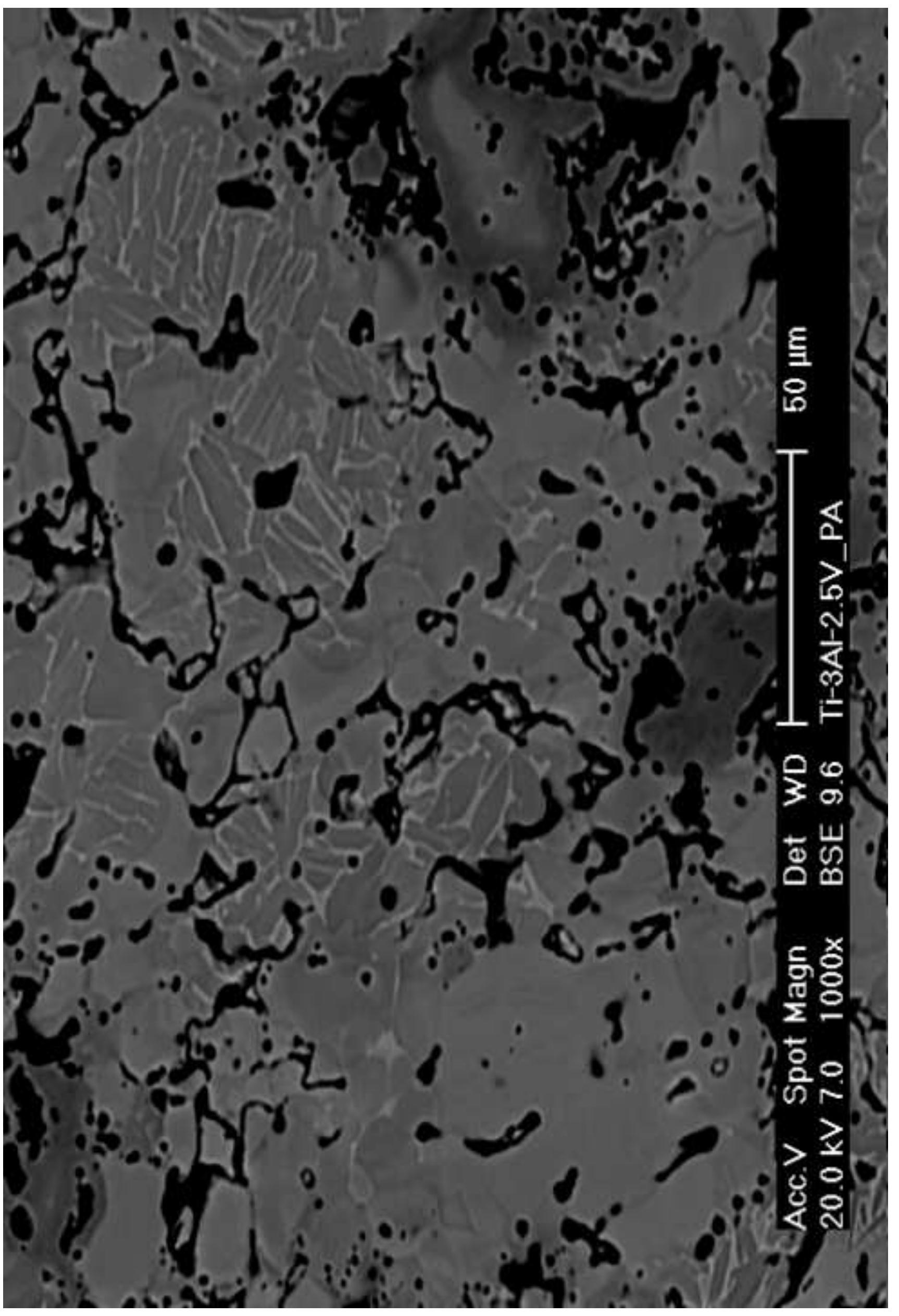




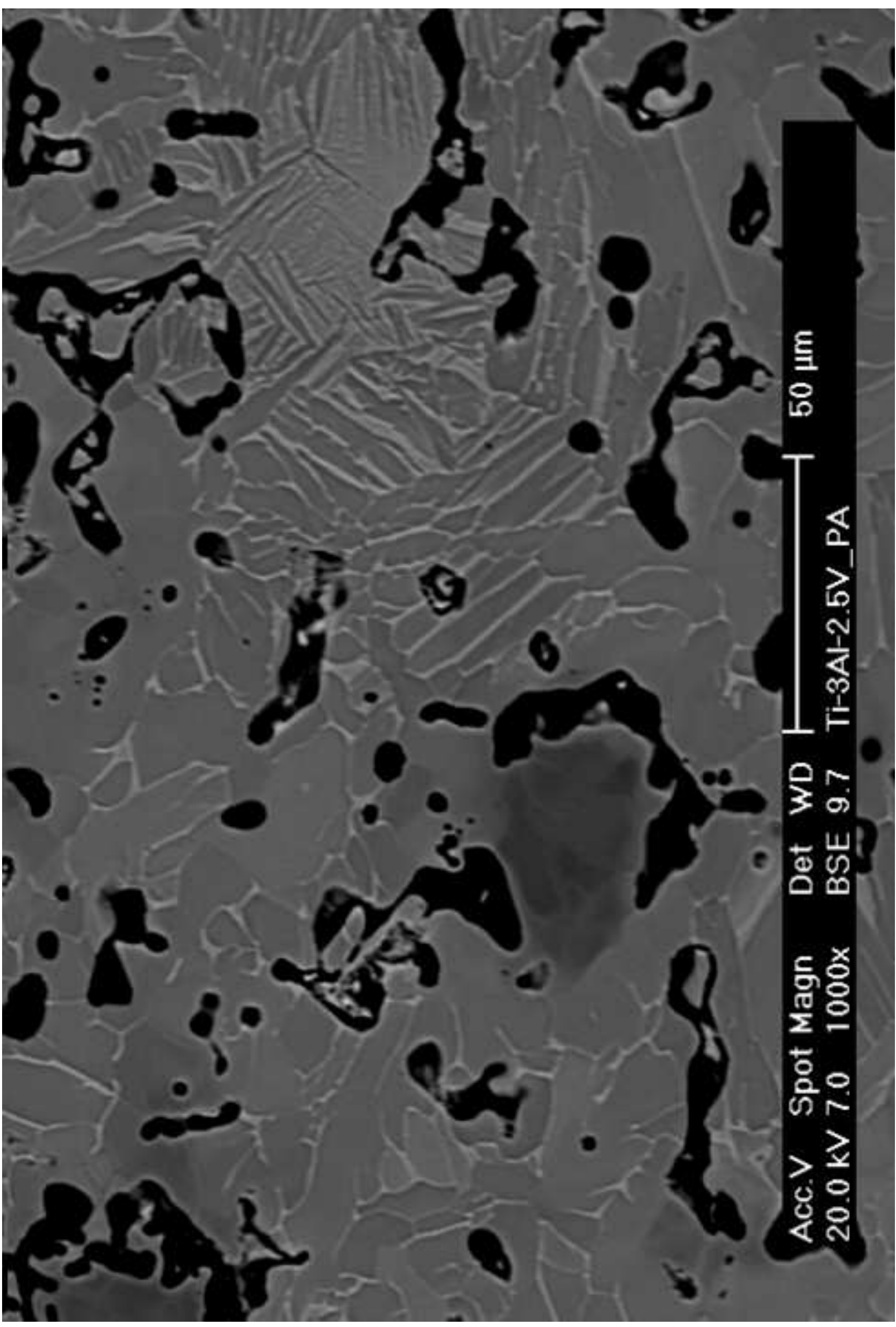




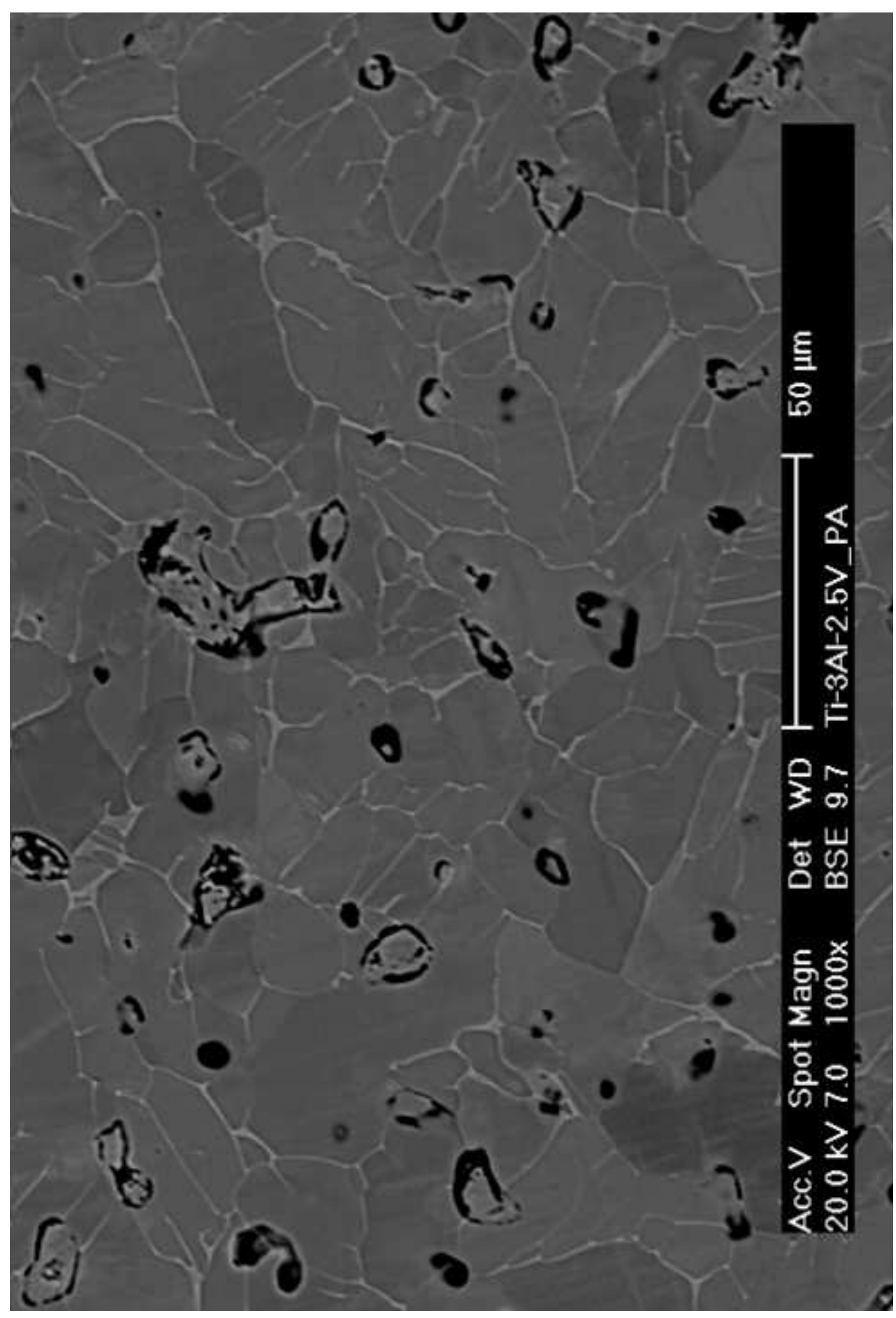




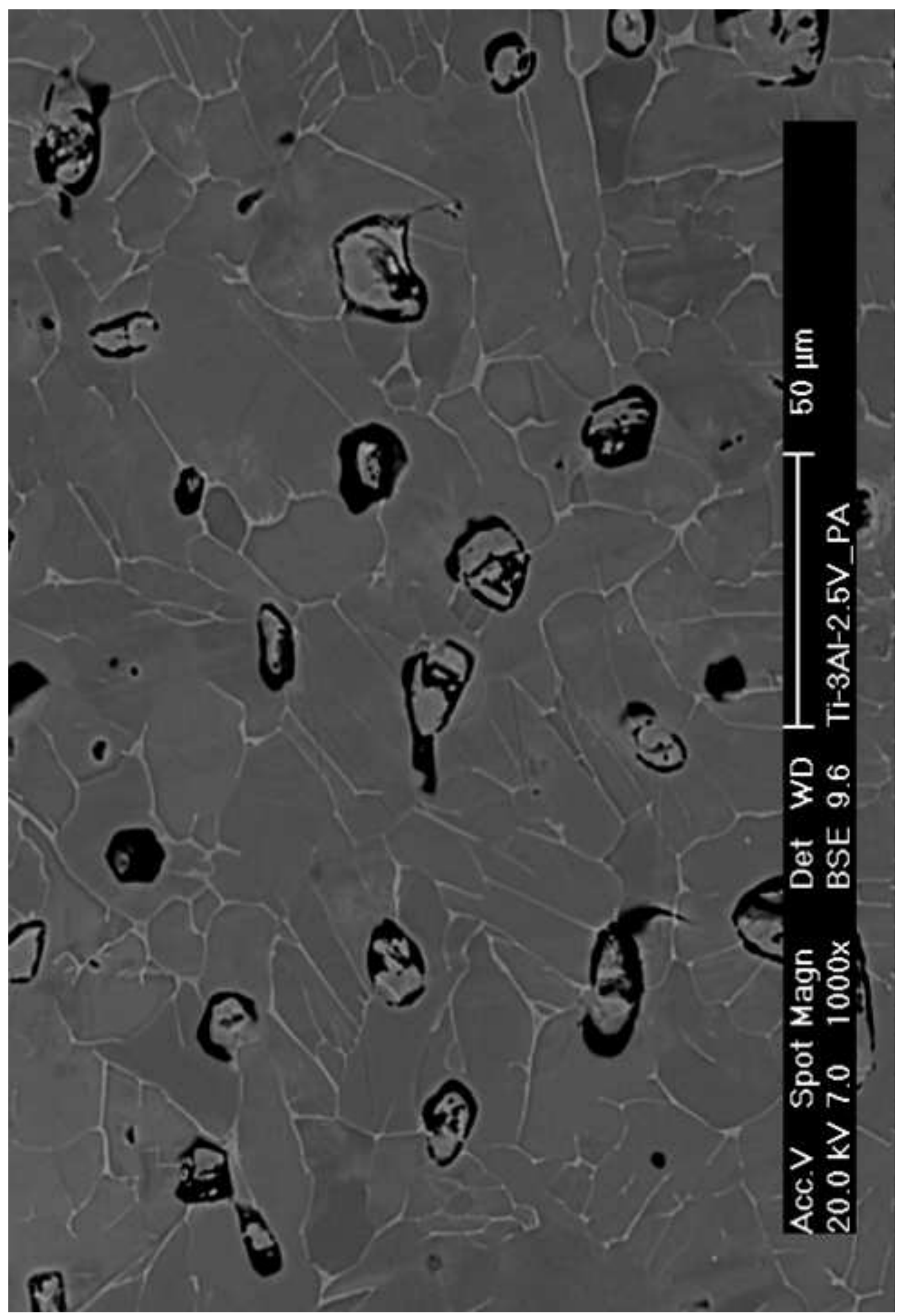




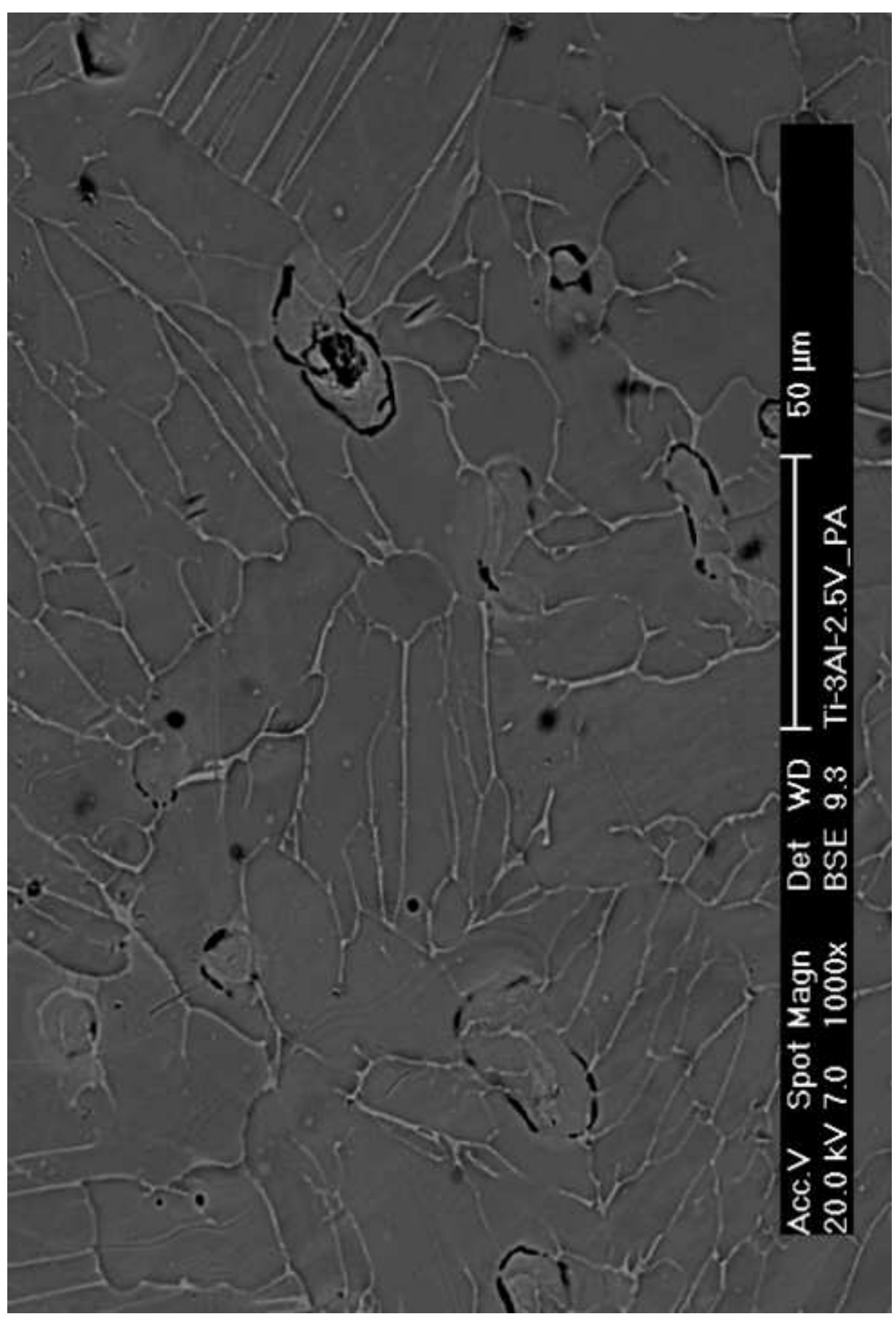




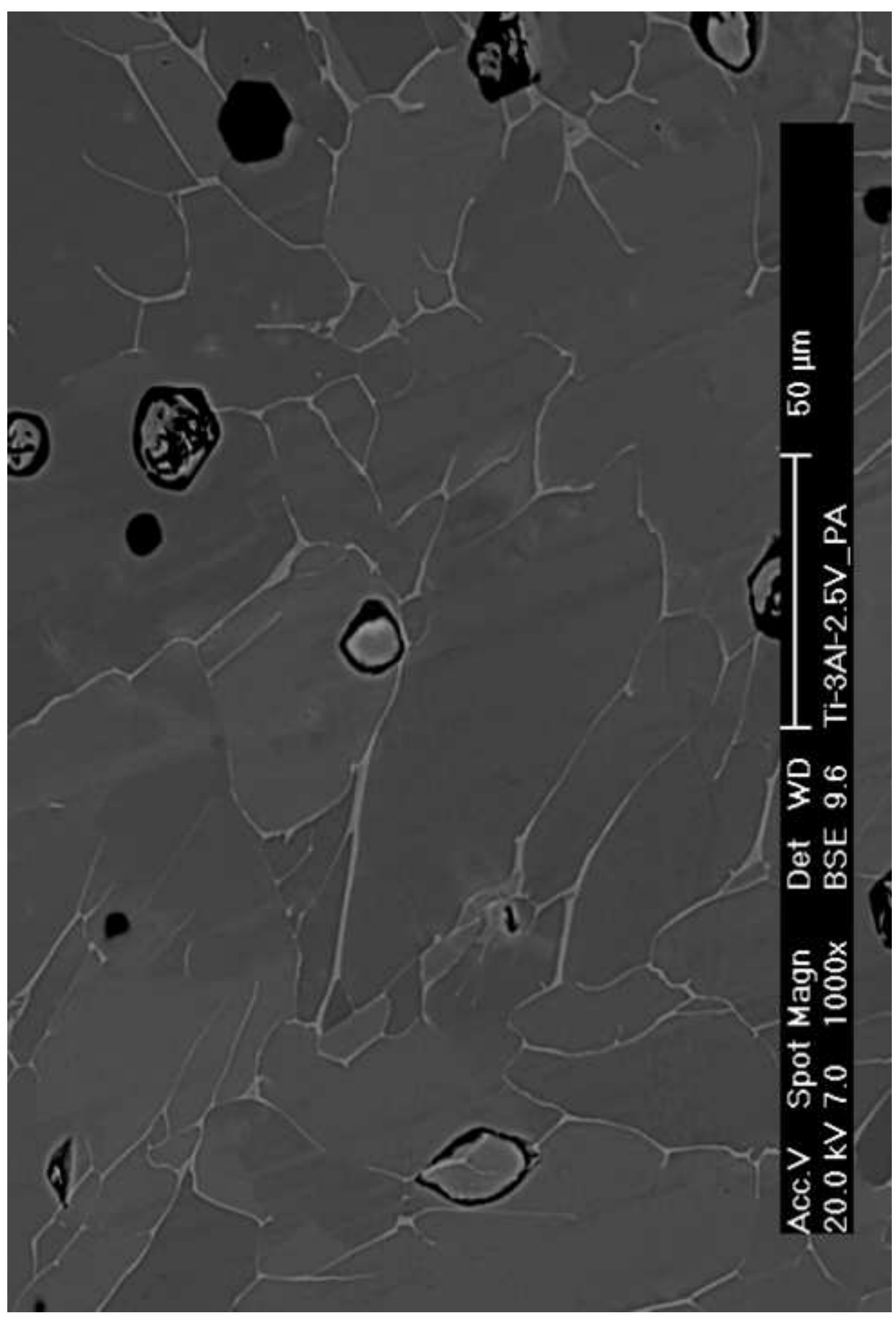




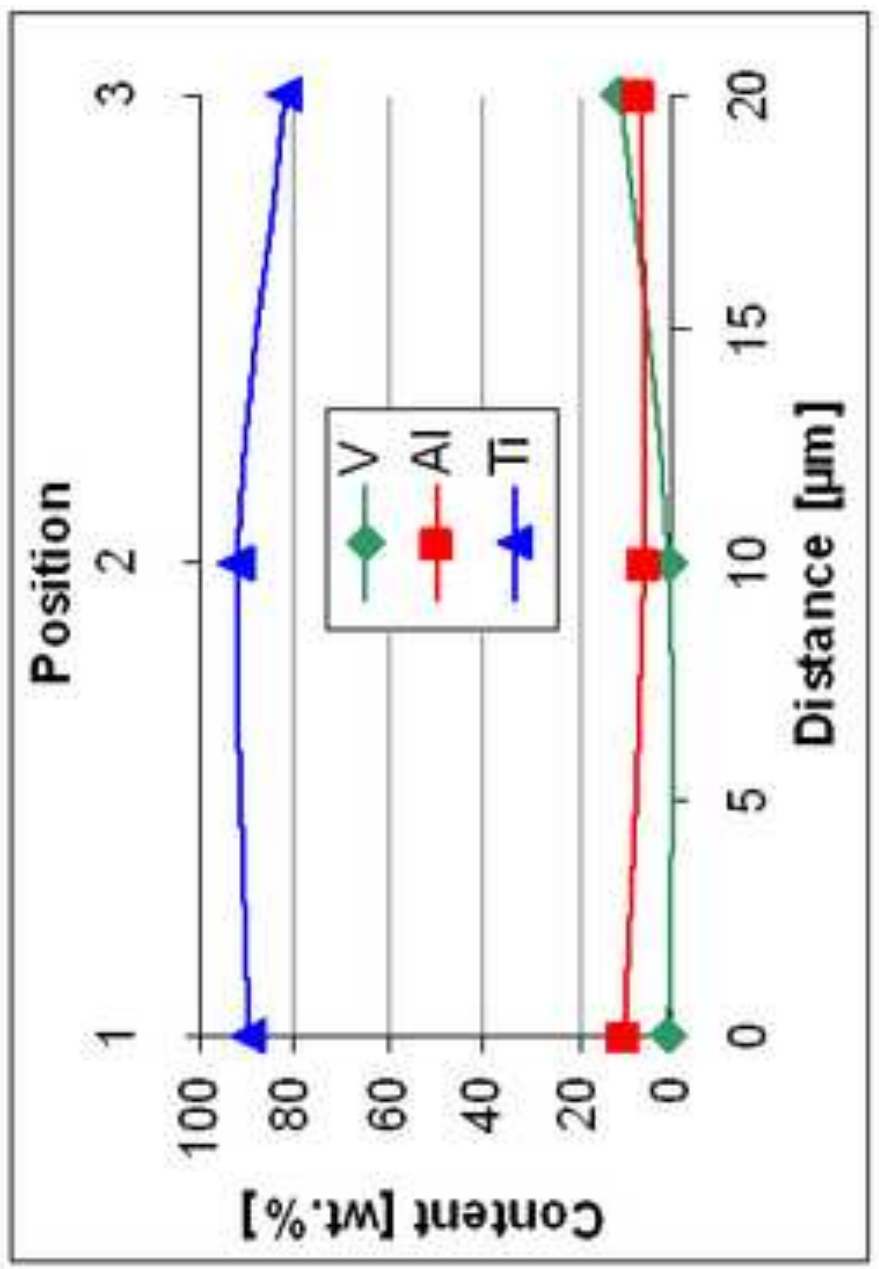

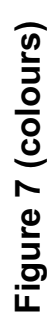






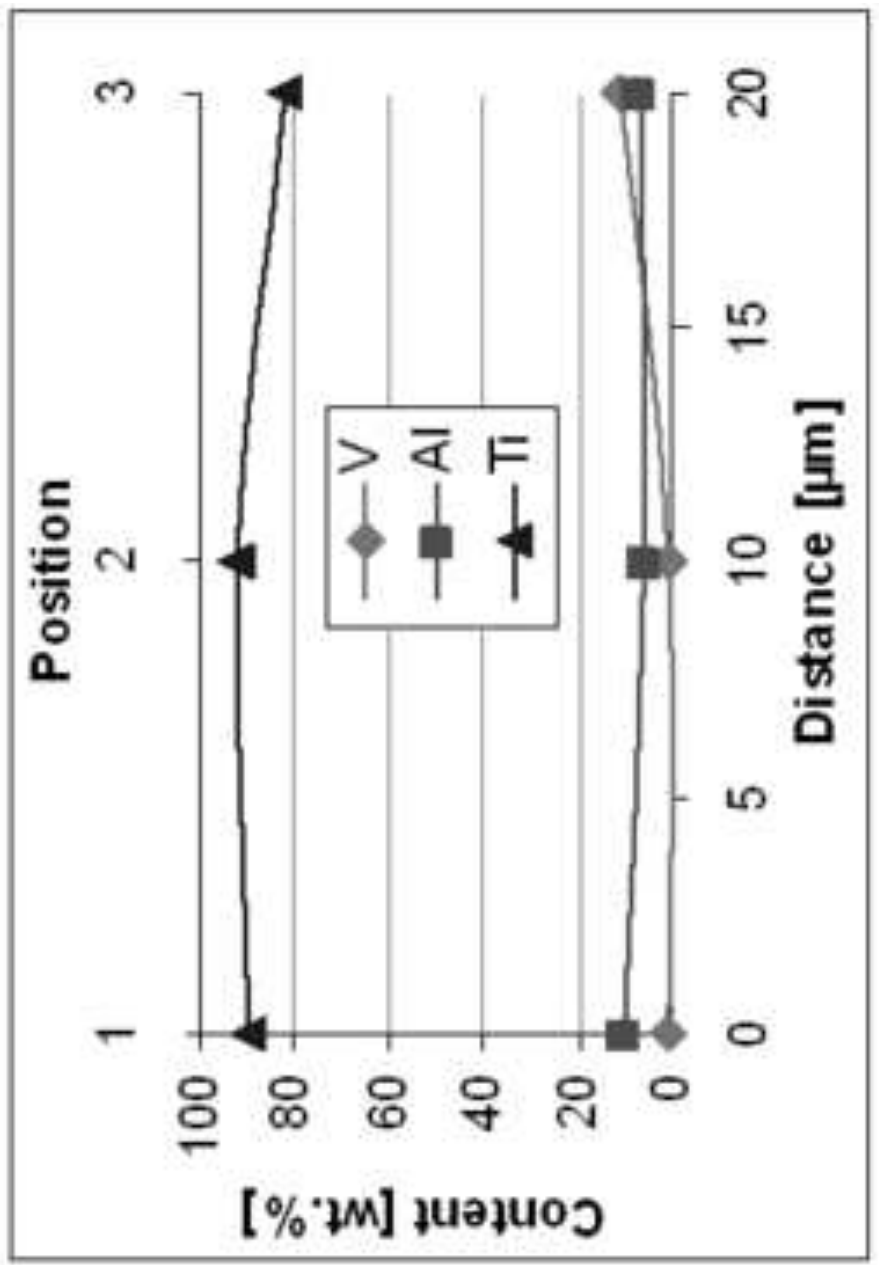

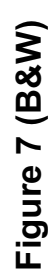

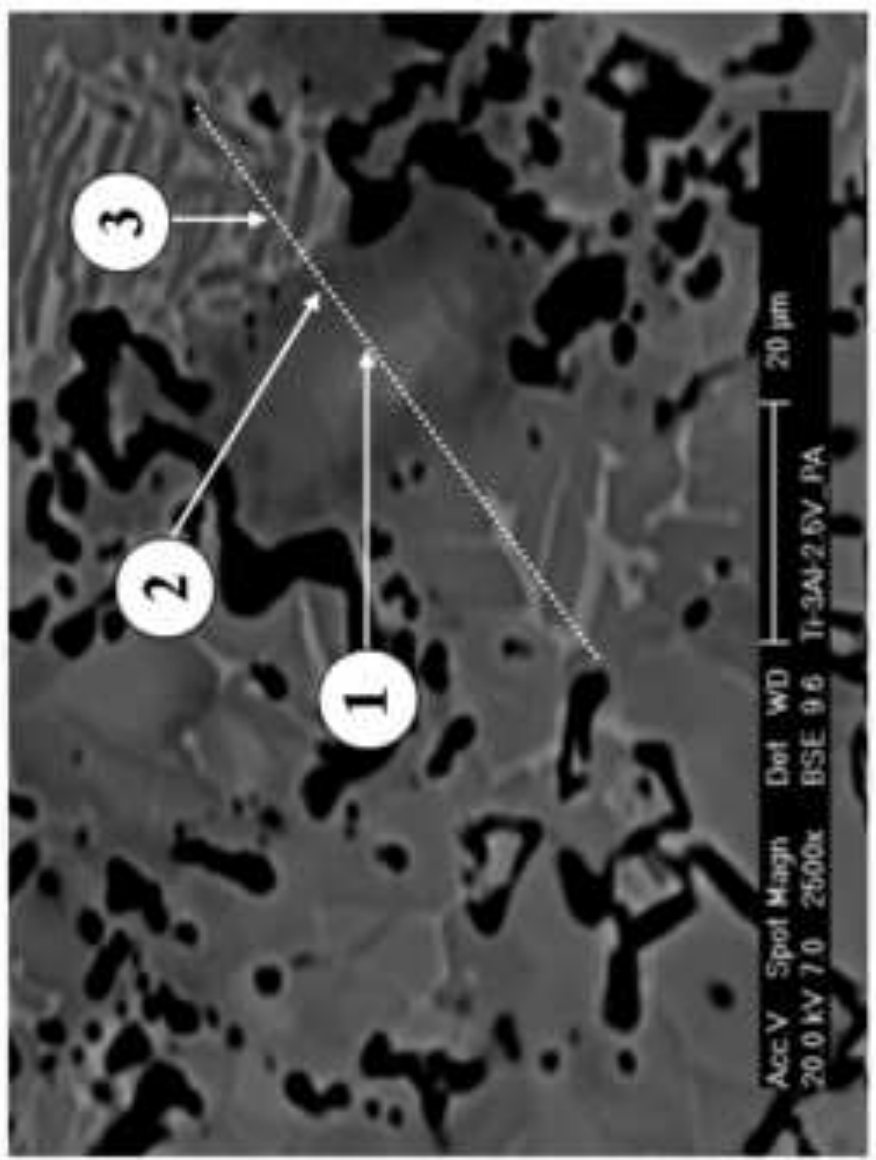




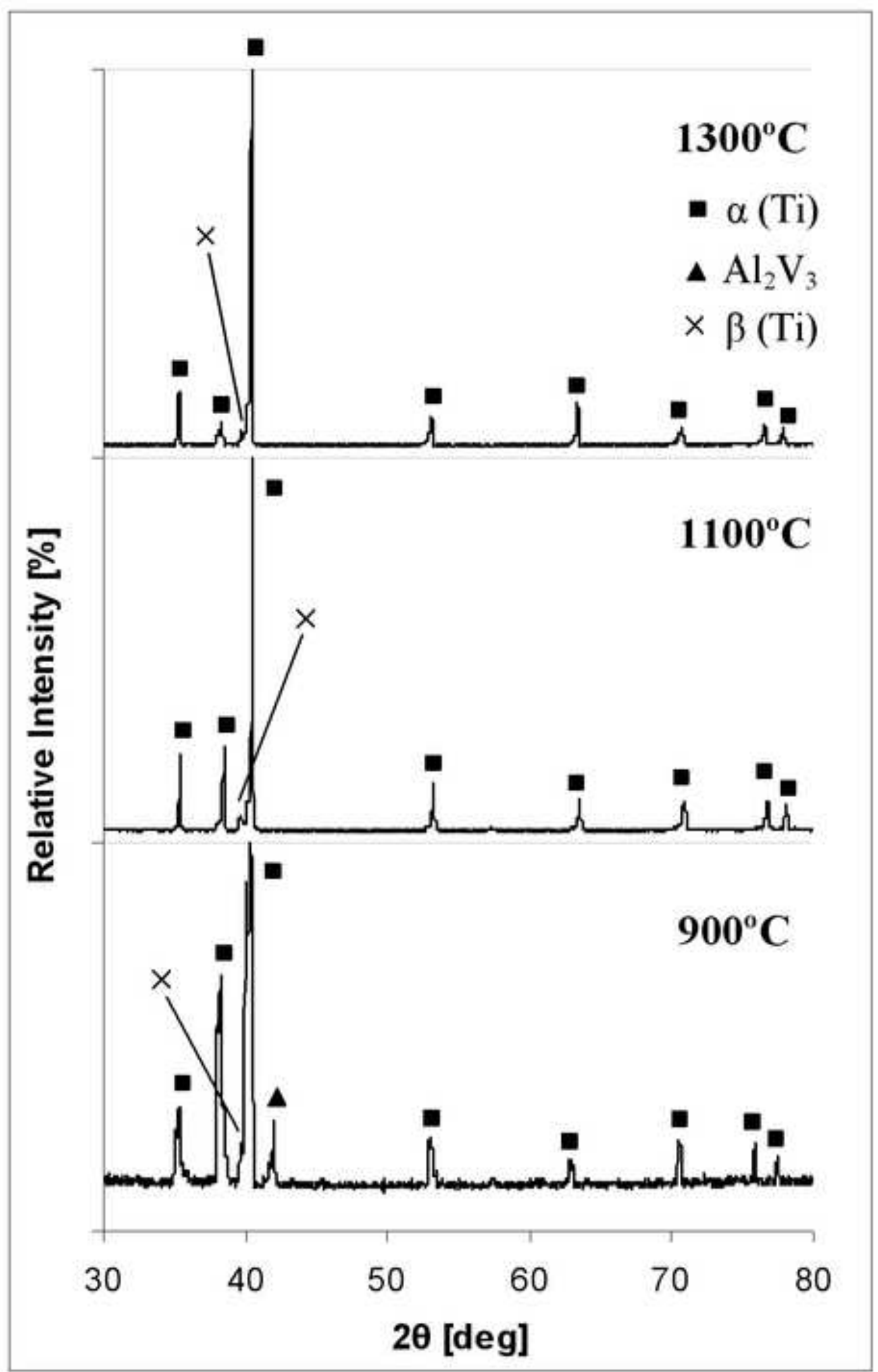

Figure 8

$1300^{\circ} \mathrm{C}$

- $\alpha$ (Ti)

- $\mathrm{Al}_{2} \mathrm{~V}_{3}$

$\times \beta(\mathrm{Ti})$

$1100^{\circ} \mathrm{C}$

$900^{\circ} \mathrm{C}$ 


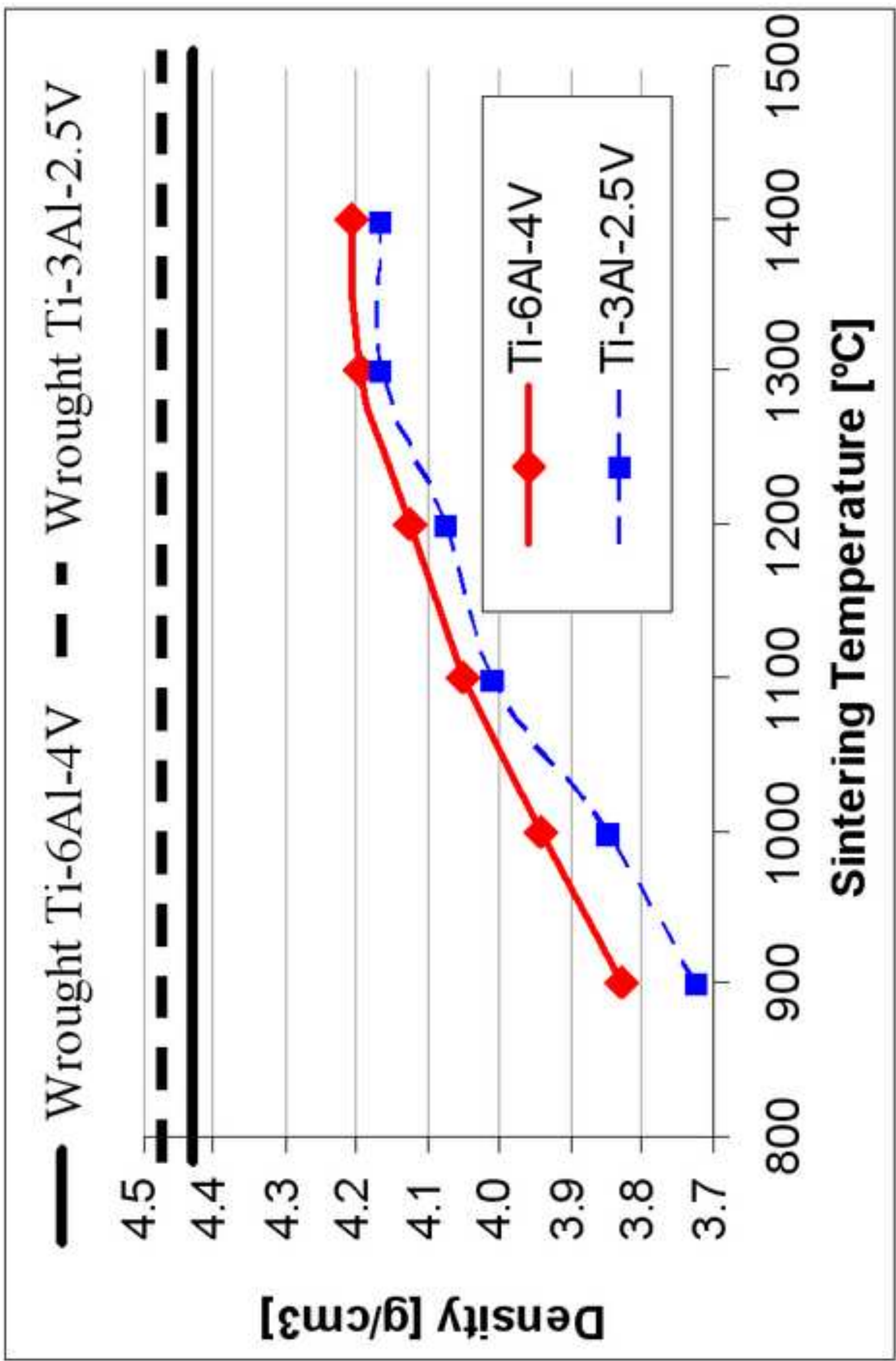




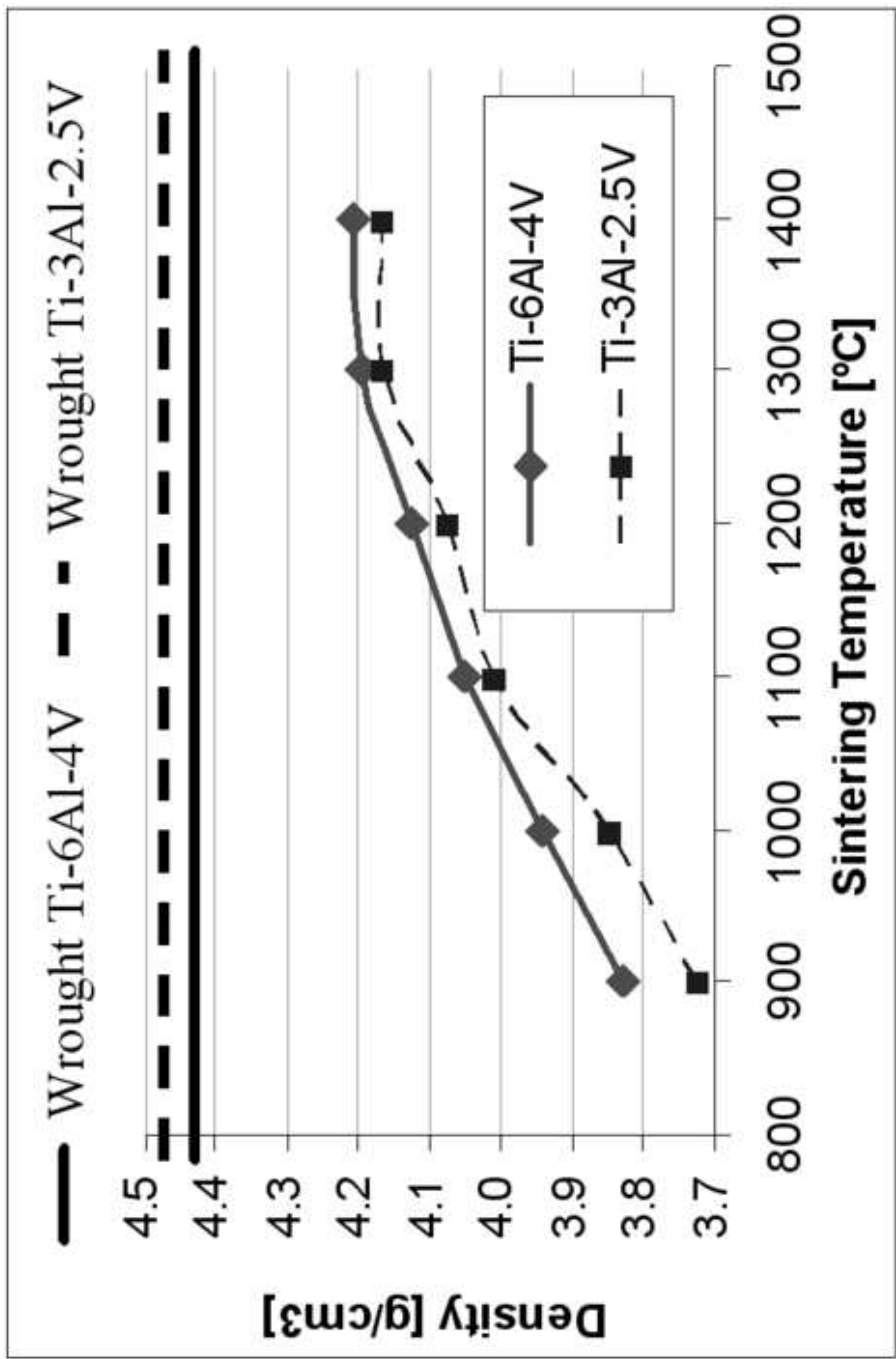



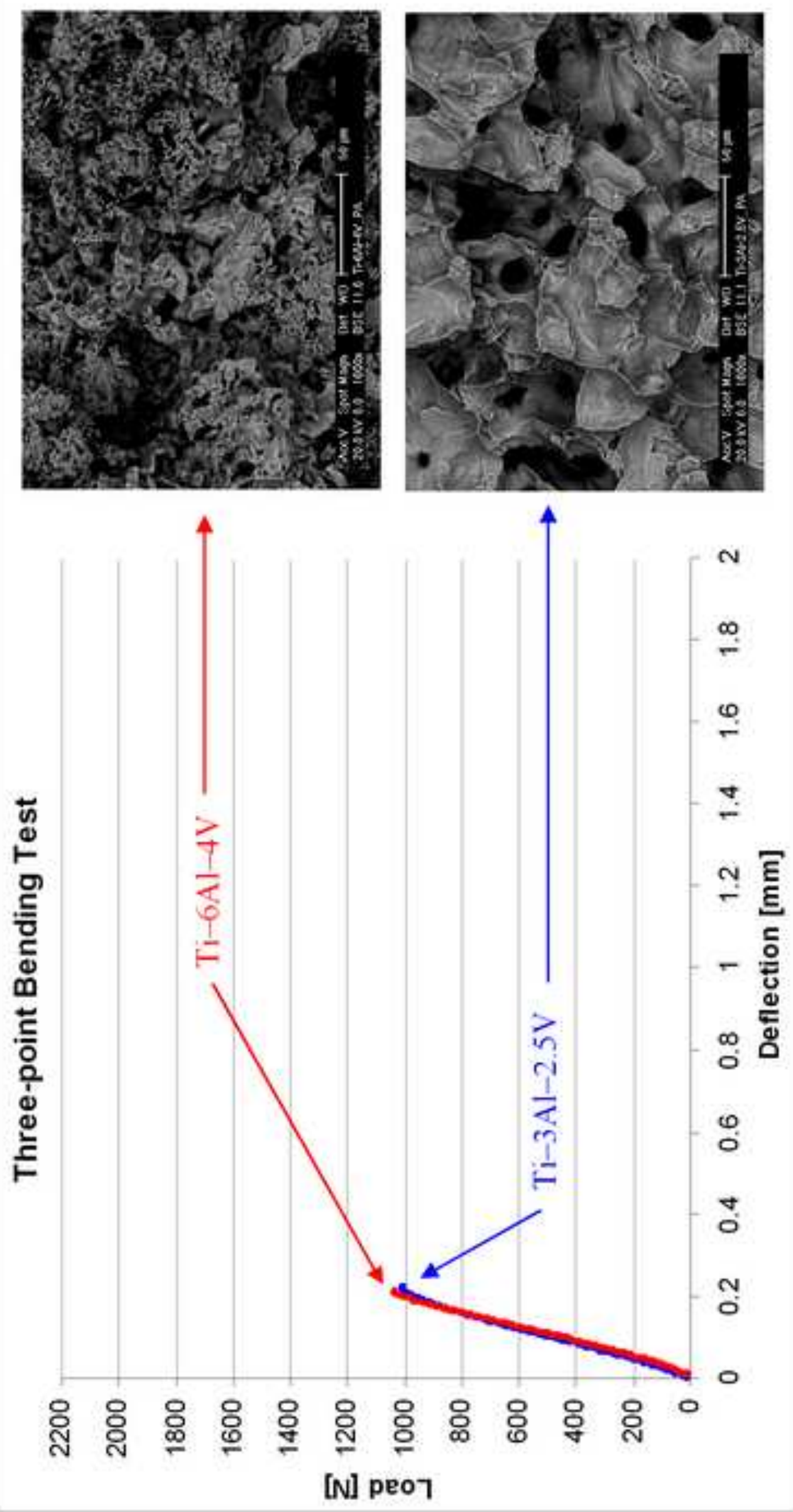

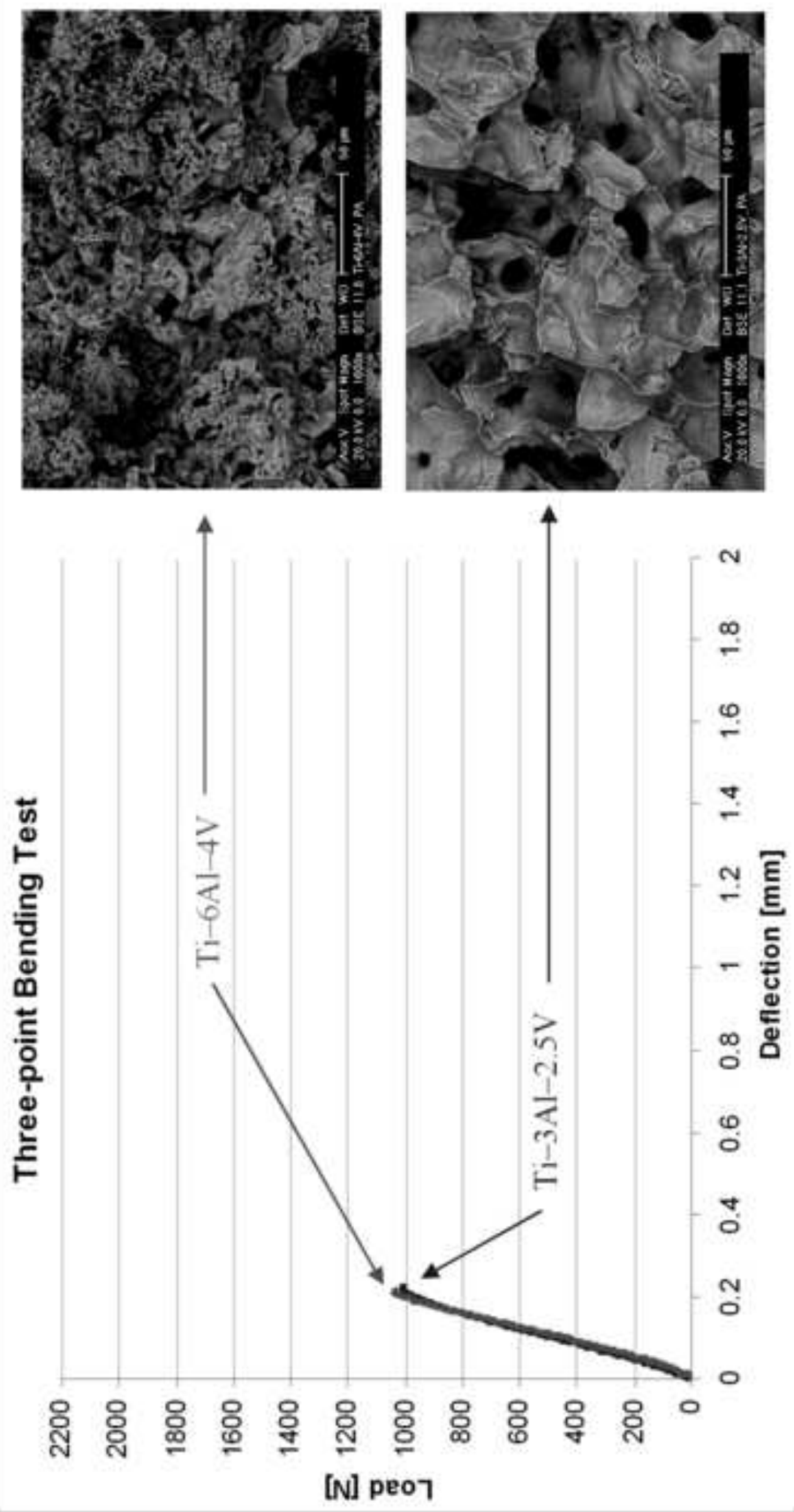

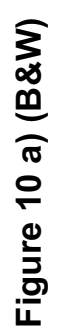




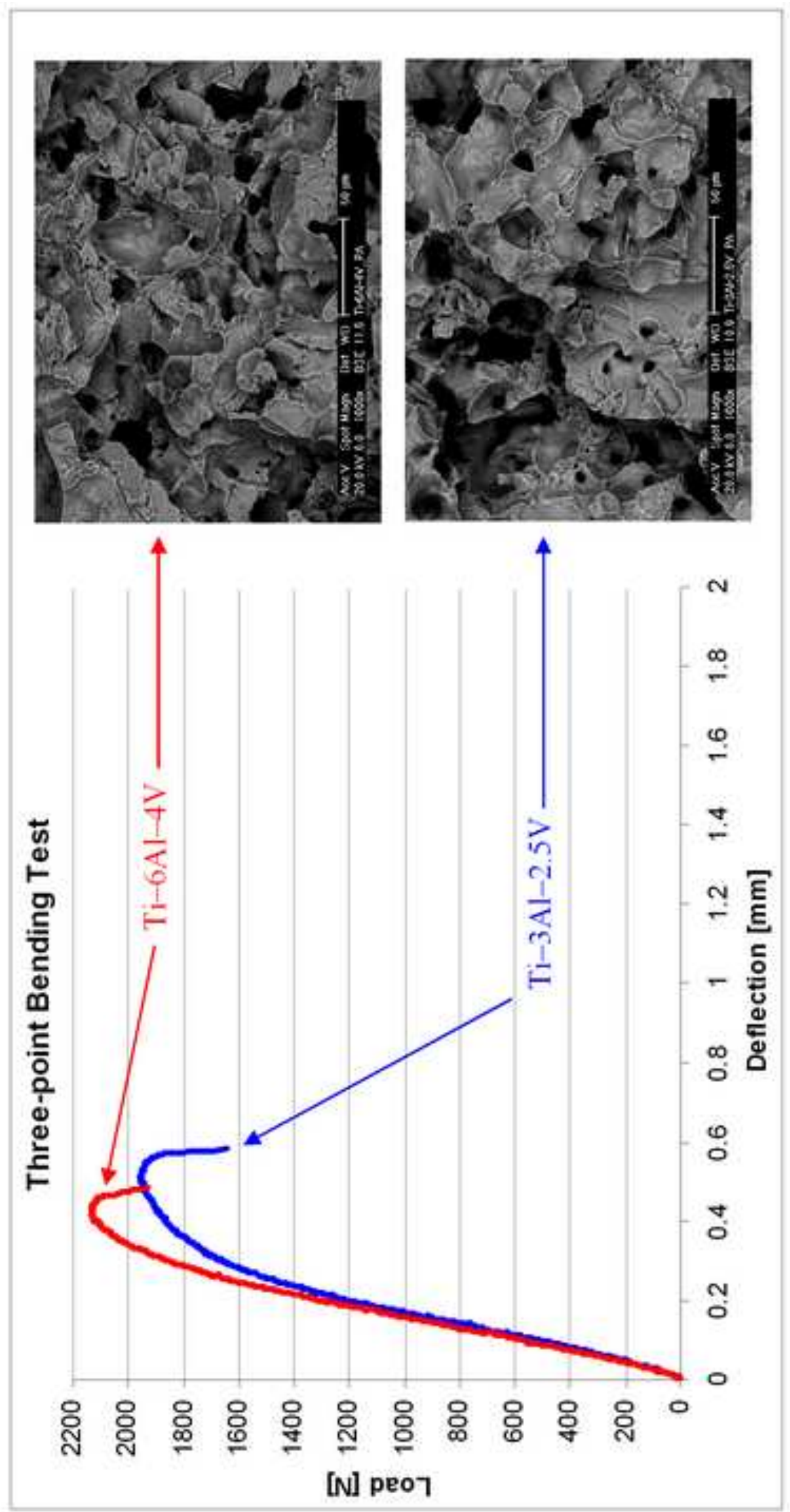

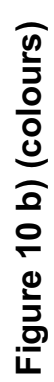



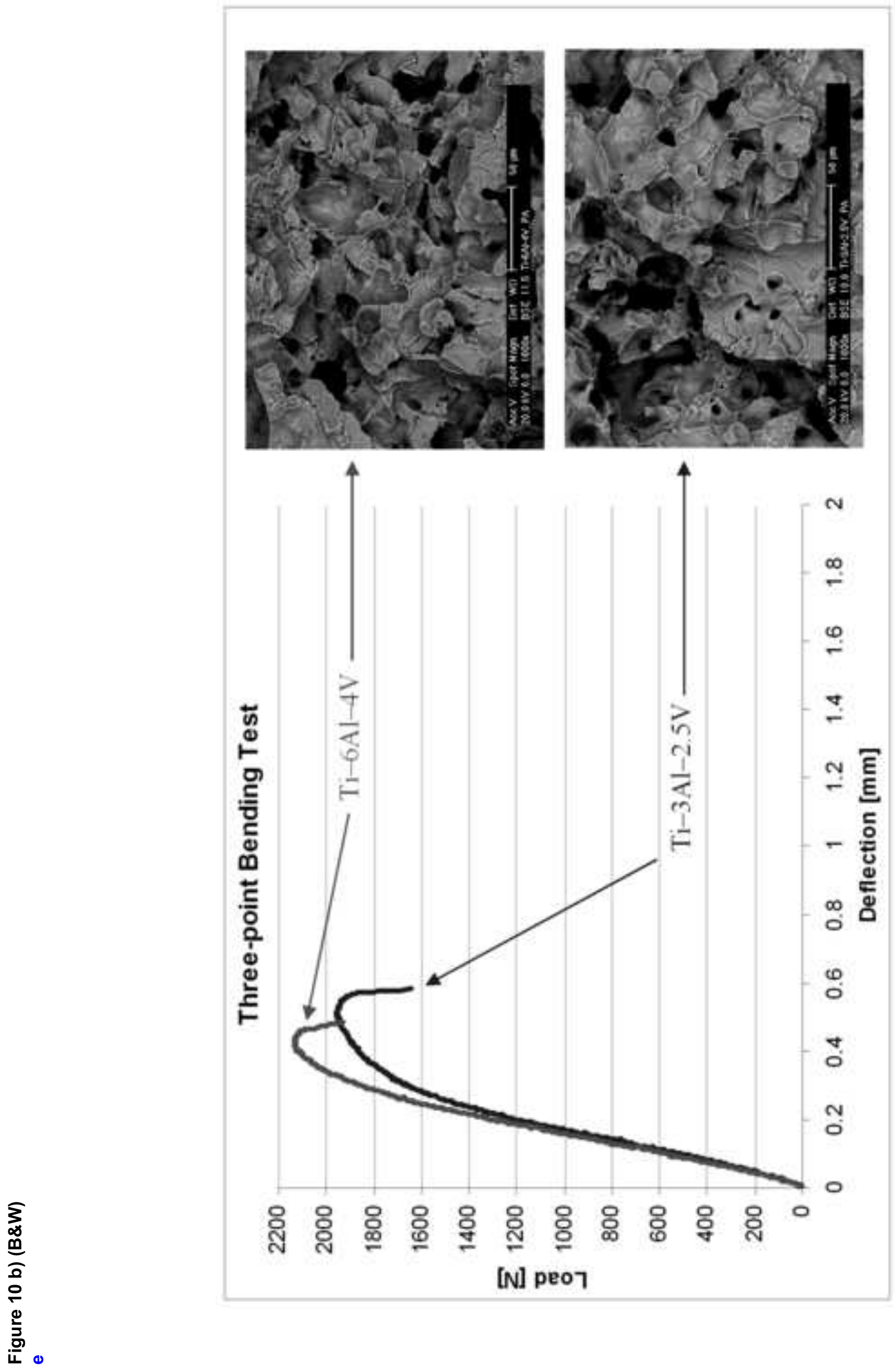


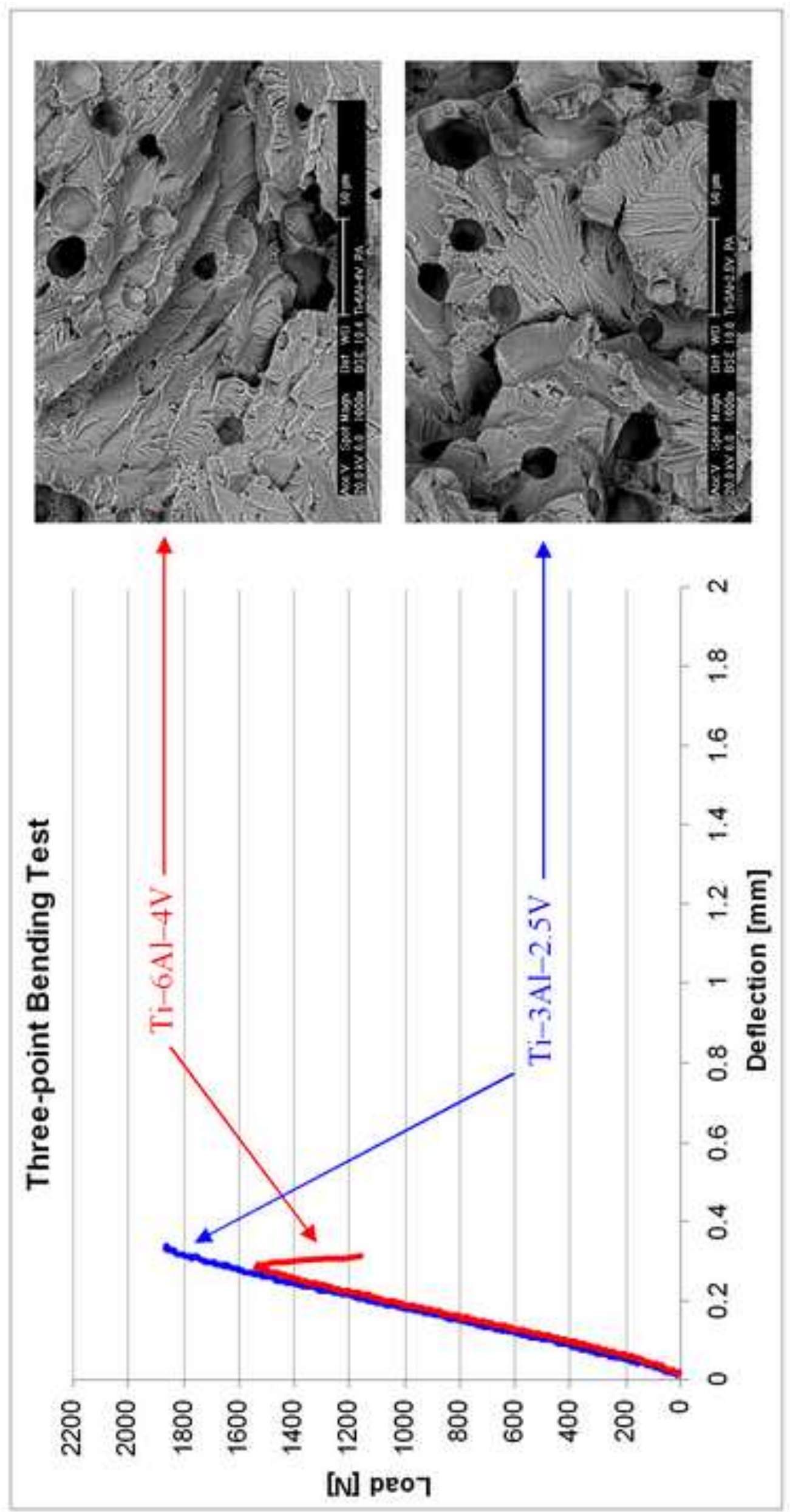



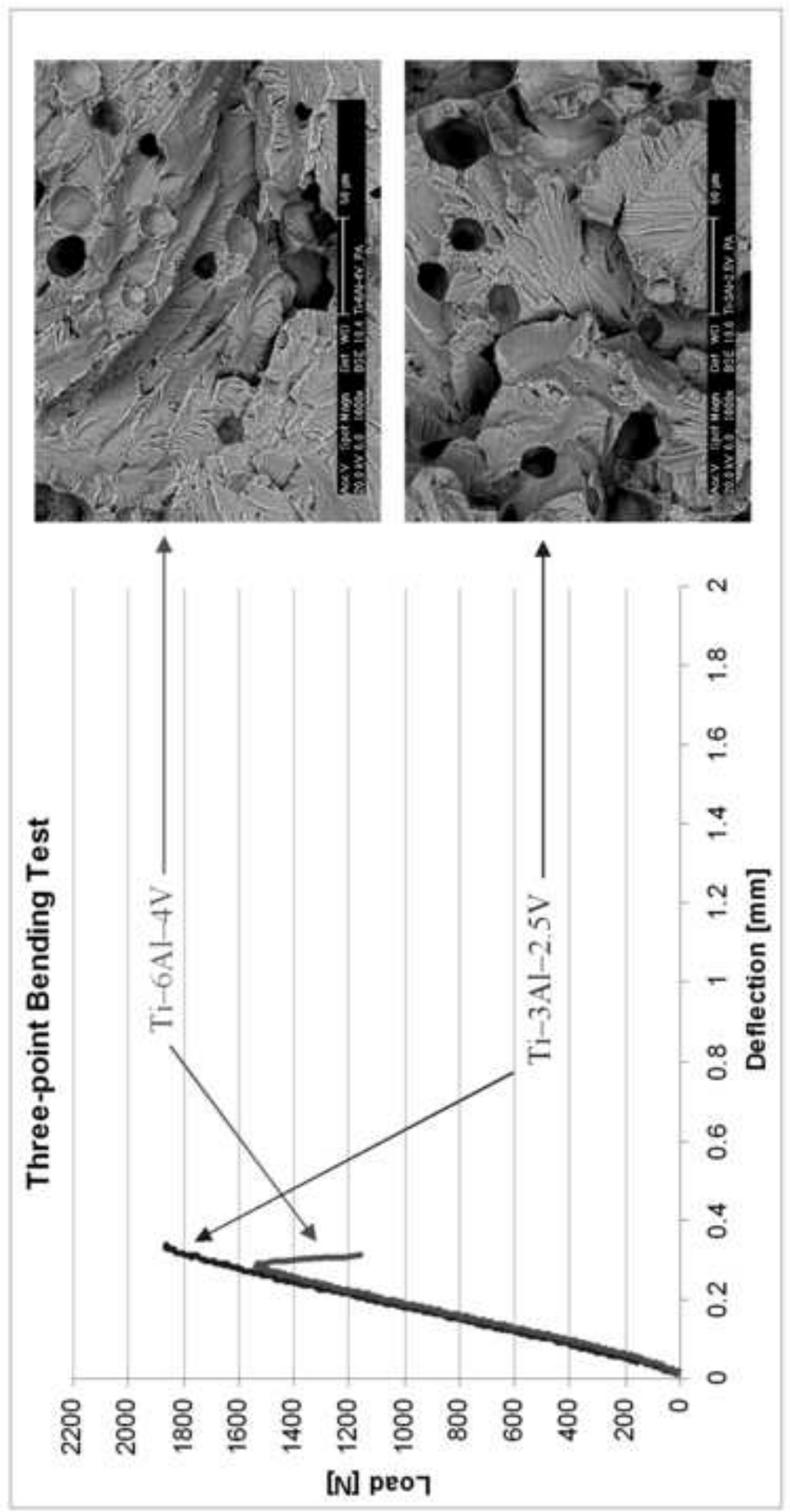

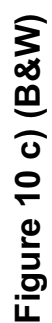




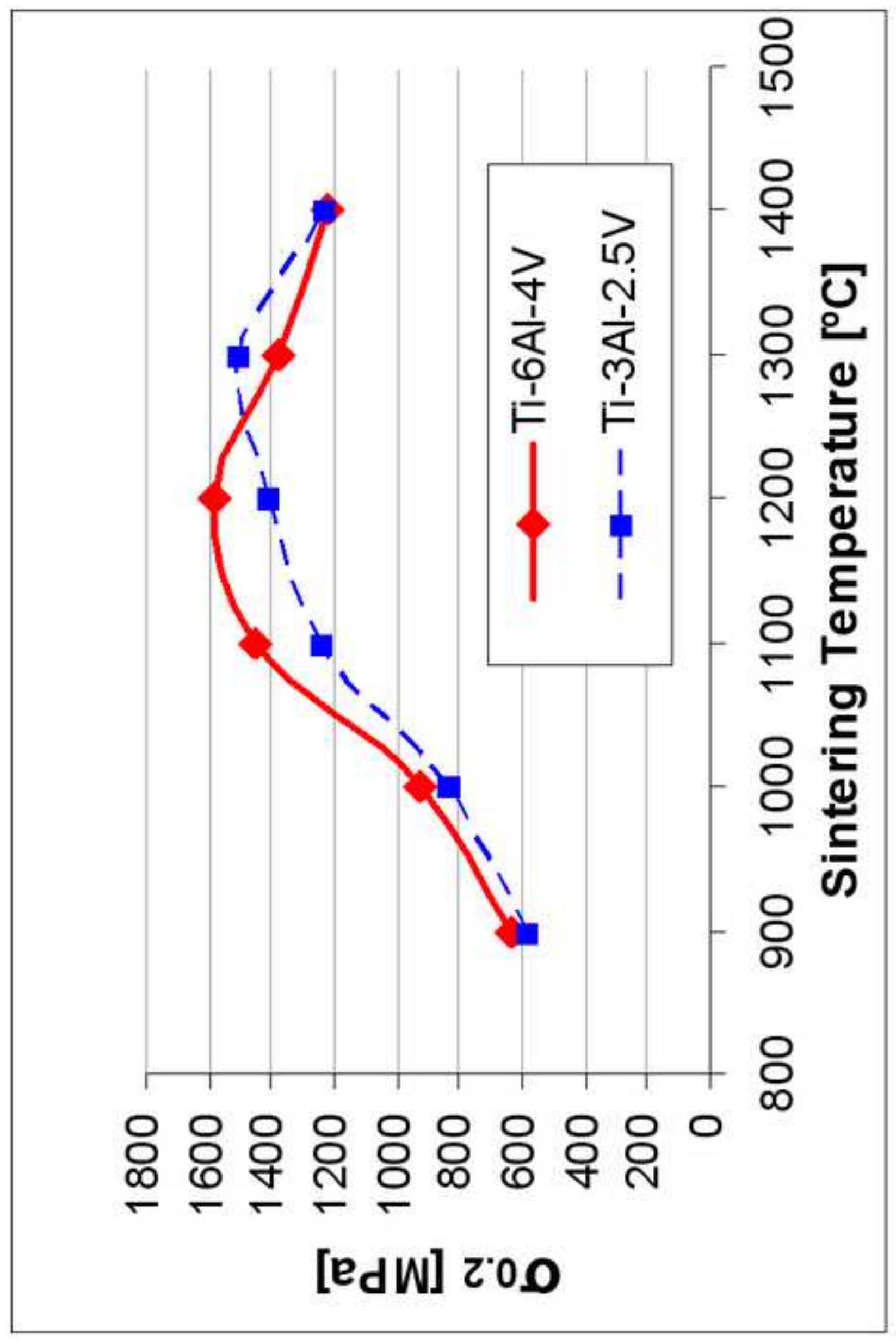




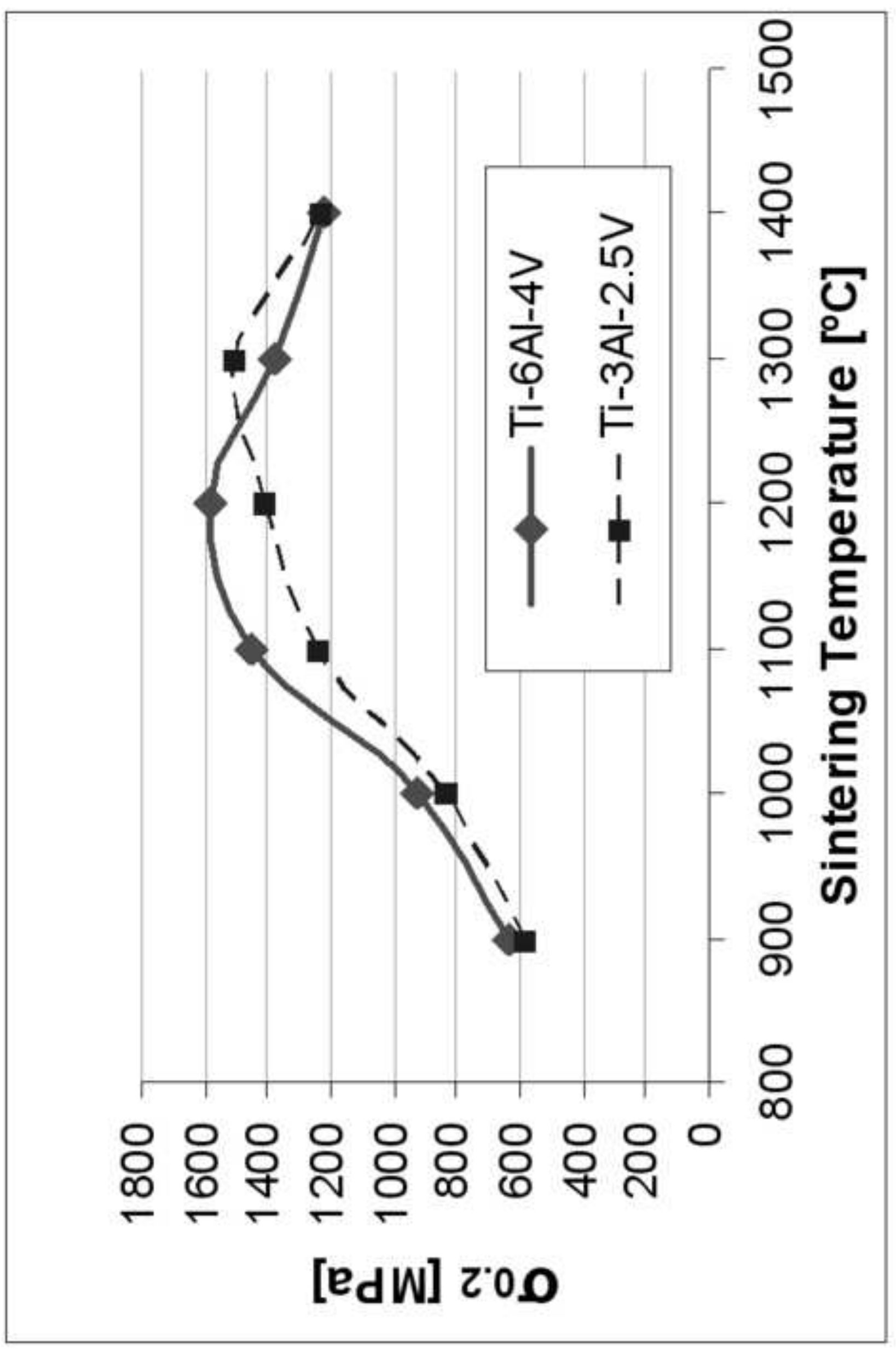




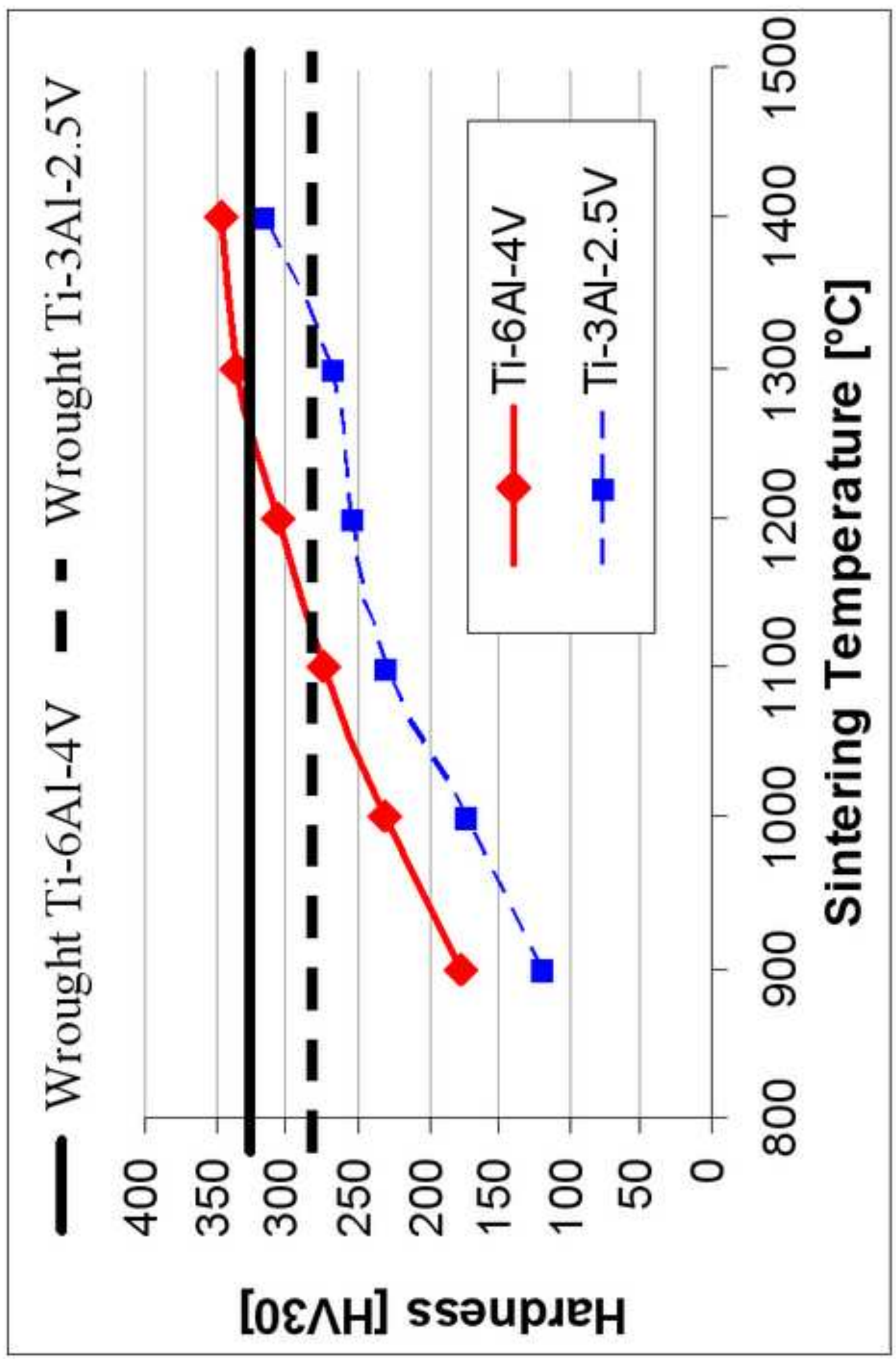



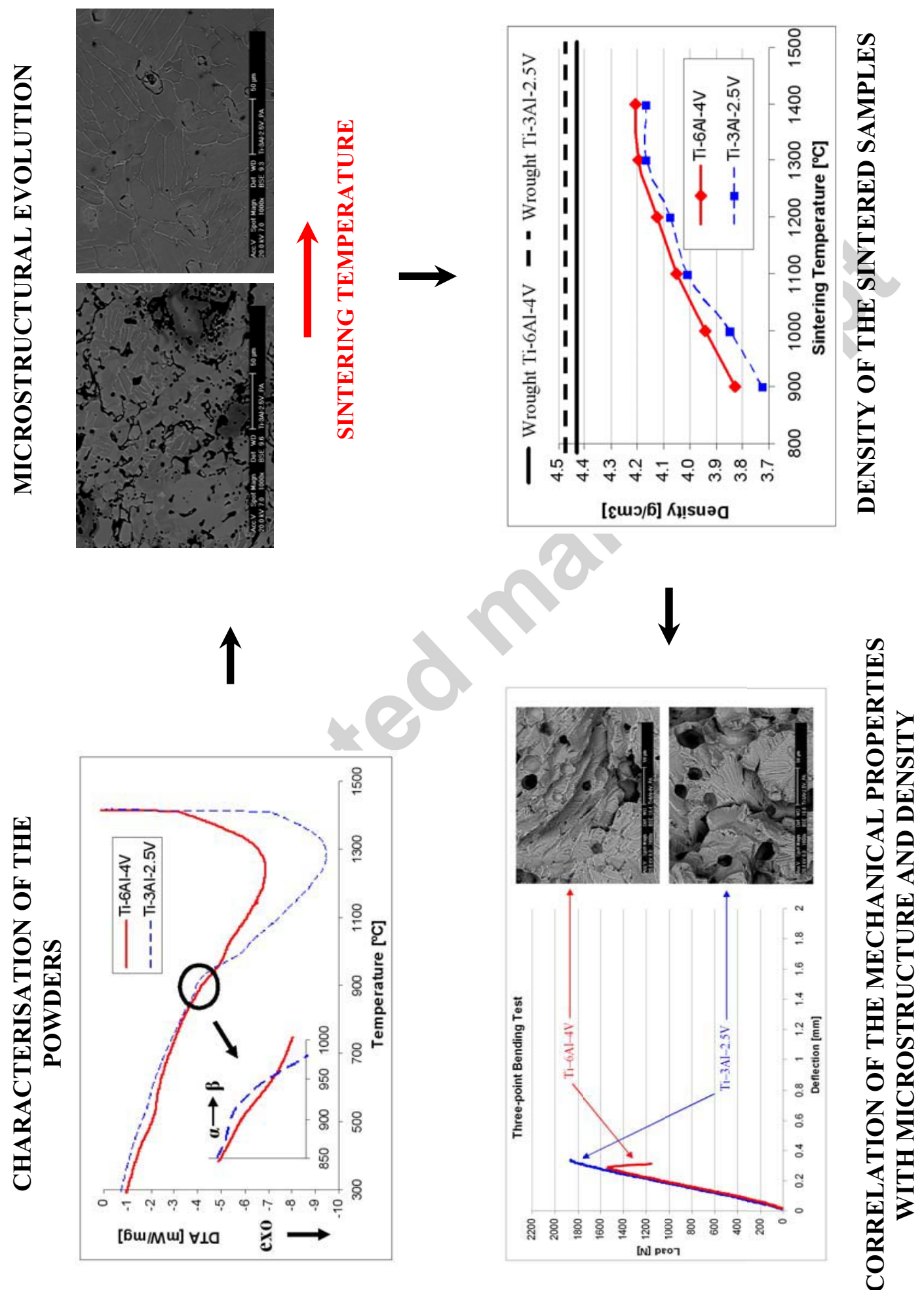